\title{
Comparative Analysis of Antiviral Responses in Brachypodium distachyon and Setaria viridis Reveals Conserved and Unique Outcomes Among $\mathrm{C}_{3}$ and $\mathrm{C}_{4}$ Plant Defenses
}

\author{
Kranthi K. Mandadi, Jesse D. Pyle, and Karen-Beth G. Scholthof \\ Department of Plant Pathology and Microbiology, Texas A\&M University, 2132 TAMU, College Station, TX 77843, U.S.A.
}

Submitted 23 May 2014. Accepted 15 July 2014.

\begin{abstract}
Viral diseases cause significant losses in global agricultural production, yet little is known about grass antiviral defense mechanisms. We previously reported on host immune responses triggered by Panicum mosaic virus (PMV) and its satellite virus (SPMV) in the model $\mathrm{C}_{3}$ grass Brachypodium distachyon. To aid comparative analyses of $\mathrm{C}_{3}$ and $\mathrm{C}_{4}$ grass antiviral defenses, here, we establish $B$. distachyon and Setaria viridis (a $\mathrm{C}_{4}$ grass) as compatible hosts for seven grass-infecting viruses, including PMV and SPMV, Brome mosaic virus, Barley stripe mosaic virus, Maize mild mottle virus, Sorghum yellow banding virus, Wheat streak mosaic virus (WSMV), and Foxtail mosaic virus (FoMV). Etiological and molecular characterization of the fourteen grassvirus pathosystems showed evidence for conserved crosstalk among salicylic acid (SA), jasmonic acid, and ethylene pathways in B. distachyon and $S$. viridis. Strikingly, expression of PHYTOALEXIN DEFICIENT4, an upstream modulator of SA signaling, was consistently suppressed during most virus infections in $B$. distachyon and $S$. viridis. Hierarchical clustering analyses further identified unique antiviral responses triggered by two morphologically similar viruses, FoMV and WSMV, and uncovered other hostdependent effects. Together, the results of this study establish $B$. distachyon and $S$. viridis as models for the analysis of plant-virus interactions and provide the first framework for conserved and unique features of $C_{3}$ and $C_{4}$ grass antiviral defenses.
\end{abstract}

Viral diseases of grasses cause significant losses in global agricultural production and productivity. The Food and Agriculture Organization (FAO) estimate of cereal yields for 2013 was 2,521 million metric tons (Mton). In the United States alone, Wheat streak mosaic virus (WSMV) is a serious threat to wheat (Triticum asestivum) production (French and Stenger 2003) and is responsible for an estimated 3 Mton of yield loss in 2012 (FAO website). WSMV can spread quickly via its mite vector, resulting in localized yield losses of up to $100 \%$ in the infected fields (Navia et al. 2013). Barley stripe mosaic virus

Corresponding author: Karen-Beth G. Scholthof; E-mail: kbgs@tamu.edu; Fax: + 1.979.845.6483.

* The $\boldsymbol{e}$-Xtra logo stands for "electronic extra" and indicates that four supplementary figures and three supplementary tables are published online and that Figures 2, 3, 5, 6, and 7 appear in color online.

(C) 2014 The American Phytopathological Society
(BSMV) causes yield losses up to 64 and $75 \%$, respectively, in barley (Hordeum vulgare) and wheat and remains a potential threat to cultivated oat (Avena sativa) (Donald and Jackson 1994; Hagborg 1954; Jackson et al. 2009). Similarly, Panicum mosaic virus (PMV) causes significant grain losses in millets, including proso millet (Panicum miliaceum), foxtail millet (Setaria italica), and pearl millet (Pennisetum glaucum). PMV is also ubiquitous along the Gulf Coast region of the United States and is the causal agent of St. Augustine decline disease of St. Augustinegrass (Stenotaphrum secundatum) (Cabrera and Scholthof 1999). Homeowners with PMV-infected St. Augustinegrass lawns waste an estimated 2.2 billion cubic meters of water annually in attempts to revive their lawns from the viral infection-enough water to fill almost 900,000 Olympic-size swimming pools. In addition to unnecessary overwatering, PMV infections also account for an estimated 54.5 million pounds of overused nitrogen fertilizer (24,000 metric tons). A recent survey of switchgrass (Panicum virgatum) breeding plots in Nebraska found PMV infecting upwards of $75 \%$ of switchgrass plots (Stewart et al. 2013), suggesting PMV as a potential threat to the biofuel industry. Although not much data is available for crop losses caused by other grass-infecting viruses, such as Brome mosaic virus (BMV), Foxtail mosaic virus (FoMV), Maize mild mottle virus (MMMV), or Sorghum yellow banding virus (SYBV), that infect wheat, barley, maize (Zea mays), millets, and sorghum (Sorghum bicolor), the cumulative economic losses due to grass viral diseases could run into hundreds of millions of dollars annually. Even with progress in identification of resistance gene loci in rice (Oryza sativa), barley, maize, and wheat (Redinbaugh and Pratt 2009; Trottet and Gouis 2004) and success in breeding resistance against some cereal-infecting viruses, there are significant gaps in our knowledge of the molecular mechanisms of monocotyledonous (monocot) host responses to virus infection (Mandadi and Scholthof 2012, 2013).

Our knowledge of plant defense mechanisms has significantly advanced over the past decade, but much of it pertains to bacterial, fungal, and, to a lesser extent, viral diseases that infect dicotyledonous (dicot) plants such as Arabidopsis (Arabidopsis thaliana), Nicotiana benthamiana, and tomato (Solanum lycopersicum) (Alvarado and Scholthof 2009; AscencioIbáñez et al. 2008; Hanssen et al. 2011; Huang et al. 2005; Jakubiec et al. 2012; Love et al. 2012; Pacheco et al. 2012; Postnikova and Nemchinov 2012; Whitham et al. 2006). Only a handful of studies are related to monocot antiviral responses (Albar et al. 2006; Jia et al. 2012; Mandadi and Scholthof 2012, 2013; Satoh et al. 2010; Shimizu et al. 2007; Ventelon- 
Debout et al. 2003), despite grasses being the primary sources of our food, forage, and bioenergy needs. This knowledge gap is primarily due to the lack of a tractable genetic model for monocots. Agronomic grasses, including rice, maize, barley, wheat, oat, and sorghum are difficult to grow in the laboratory, require substantial greenhouse space, and have long seed-toseed lifecycles. Recently, owing to advances in genomics and sequencing initiatives, akin to Arabidopsis, genetically tractable grasses such as Brachypodium distachyon (a $\mathrm{C}_{3}$ grass) and Setaria viridis (a $\mathrm{C}_{4}$ grass) have gained the status of model grasses because of their high degree of genome collinearity and phylogenetic relatedness to the field grasses (Fig. 1) (Bennetzen et al. 2012; Brutnell et al. 2010). In addition, both $B$. distachyon and $S$. viridis fulfill the requisite traits needed in a model plant, including small stature, rapid seed-to-seed life cycle, small and fully sequenced genomes, and ease of Agrobacterium-mediated transformation. The functional genomic and genetic resources for $B$. distachyon also include diverse geographical accessions, mutant collections, and yeast twohybrid libraries (Bennetzen et al. 2012; Brutnell et al. 2010; Brkljacic et al. 2011; Cao et al. 2011; International Brachypodium Initiative 2010; Mur et al. 2011).

We and others have used B. distachyon to investigate antiviral immune responses triggered by PMV (Mandadi and Scholthof 2012) and BSMV (Cui et al. 2012). BSMV is a positive-sense, single-stranded (ss)RNA virus with a tripartite genome and is the type member of the Hordeivirus genus in the family Virgaviridae (Bragg and Jackson 2004; Donald and Jackson 1994; Jackson et al. 2009). Using B. distachyon as a host, Cui and associates (2012) identified the first dominant resistance gene $(B S R 1)$ in grasses that confers resistance against BSMV. The resistance is accompanied by a hypersensitive response (HR) and necrosis-like symptoms and is presumed to be a result of interaction between the putative $B$. distachyon BSR1 protein and the BSMV triple gene block 1 (TGB1) movement protein (Cui et al. 2012; Lee et al. 2012).

PMV is a positive-sense ssRNA virus that is the type member of the Panicovirus genus in the family Tombusviridae and infects several Poaceae grasses (Turina et al. 1998, 2000). PMV also supports the replication of a positive-sense ssRNA satellite virus, SPMV (Scholthof 1999) and satellite RNAs

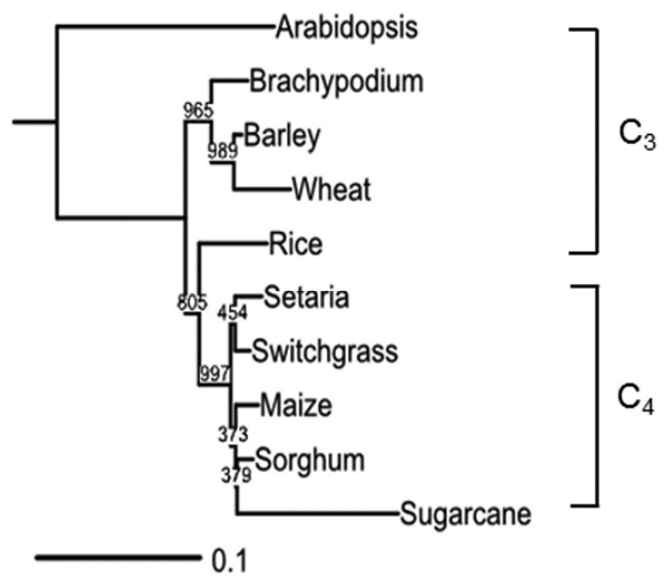

Fig. 1. Phylogenetic relationships of the $\mathrm{C}_{3}$ and $\mathrm{C}_{4}$ grasses and Arabidopsis. The species tree was constructed by multiple sequence alignment of an approximately 1,000-amino acid long concatenated super sequence corresponding to six conserved proteins from the different grasses and Arabidopsis. These sequences represent $S$-adenosyl methionine decarboxylase, glyceraldehyde-3-phosphate dehydrogenase, chlorophyll a/b-binding protein P26, catalase, $\alpha$-tubulin, and heat-shock protein 70 (Vogel et al. 2006). Bootstrap results for 1,000 replicates are shown at the nodes and the branch lengths indicate genetic distances.
(Cabrera and Scholthof 1999; Cabrera et al. 2000). PMV+ SPMV infection results in a unique synergism that is characterized by severe disease symptoms in the host plants. Taking genomic approaches, we analyzed transcriptomic changes occurring in $B$. distachyon in response to infection by PMV and PMV+SPMV (Mandadi and Scholthof 2012). From this, we identified both conserved and unique grass antiviral defense responses compared with dicot antiviral responses. For example, during PMV or PMV+SPMV infection, multiple genes in salicylic acid (SA) hormone production and signaling, including SALICYLIC ACID INDUCTION DEFICIENT2/ISOCHORISMATE SYNTHASE1, ALTERNATE OXIDASE1A (AOX1A), WRKY transcription factors, and pathogenesis-related (PR) proteins were up-regulated, while components of jasmonic acid (JA) and ethylene (ET) signaling, LIPOXYGENASE2 (LOX2), ALLENE OXIDE SYNTHASE (AOS), FATTY ACID DESATURASE7 (FAD7), VEGETATIVE STORAGE PROTEIN1 (VSP), and ETHYLENE RESPONSE FACTOR (ERF) were down-regulated. These results also support the existing concept of SA-JA crosstalk, which is largely based on studies of dicot hosts (Pieterse et al. 2012; Thaler et al. 2012). Whether the SA-JA crosstalk is a conserved feature among other grass-virus interactions and among other grass clades (e.g., $\mathrm{C}_{3}$ vs. $\mathrm{C}_{4}$ species) is not known.

To facilitate comparative analyses of antiviral defense responses, we established $B$. distachyon (a $\mathrm{C}_{3}$ grass) and $S$. viridis (a $\mathrm{C}_{4}$ grass) as amenable host platforms for seven agronomically important grass-infecting viruses in diverse genera including PMV (genus: Panicovirus) and SPMV, BSMV (genus: Hordeivirus), BMV (genus: Bromovirus), WSMV (genus: Tritimovirus), FoMV (genus: Potexvirus), MMMV (genus: putative Panicovirus), and SYBV (genus: unknown) (Table 1). We characterized disease etiology, phenotypic perturbations, and gene expression changes of thirteen defense markers in SA, JA, and ET signaling in the fourteen grass-virus combinations. Our analyses uncovered conserved, virus-specific, and host-dependent alterations in defense responses, as well as antagonistically modulated SA-JA defense components in $\mathrm{C}_{3}$ and $\mathrm{C}_{4}$ grass types during virus infection.

\section{RESULTS}

\section{B. distachyon and $S$. viridis are hosts for diverse monocot-infecting viruses.}

The PMV+SPMV co-infection induces severe symptoms of chlorosis and necrosis on leaves, decreases seed-set, and causes stunting and overall loss of biomass in B. distachyon (Mandadi and Scholthof 2012). These symptoms mimic those of PMV+SPMV infection on field grasses, such as pearl millet (Scholthof 1999), proso millet (Buzen et al. 1984), and switchgrass (Sill and Pickett 1957). To test if B. distachyon is a host for other grass-infecting viruses, we selected six additional viruses from diverse genera with wide host ranges, including BSMV, BMV, MMMV, SYBV, WSMV, and FoMV (Table 1). B. distachyon plants at the two- to three-leaf stage were inoculated with the different viruses, and disease progression was monitored up to 42 days postinoculation (dpi). To be consistent in the interpretation of results of independent infections, we established a timeline for disease progression based on the extent of phenotypic symptoms on systemically infected plants. The disease phenotypes at stages I (10 dpi), II (21 dpi), and III (42 dpi) are characterized by mild, moderate, and severe chlorosis or necrosis symptoms, respectively. In agreement with our previous findings (Mandadi and Scholthof 2012), PMV+SPMV infection induced symptoms of chlorosis and necrosis on upper noninoculated leaves as early as stage I and stunted the infected plants by stage II (Fig. 2; Supplementary Fig. S1). Infections of BSMV, WSMV, and FoMV also 
induced similar symptoms of chlorosis and necrosis on leaves by stage I and reduced the overall plant height by stage II. BMV and MMMV were the most aggressive viruses, causing severe necrosis on both inoculated and noninoculated leaves by stage I and decimating the plants shortly after stage II (Fig. 2). In WSMV and FoMV infections, although symptoms were less severe than those caused by BMV or MMMV infections, the diseased $B$. distachyon plants died shortly after stage II. In contrast to the other virus infections, symptoms on SYBVinfected $B$. distachyon were slow to appear with only mild chlorosis at stage II, which became more prominent by stage III. The effects of SYBV infection on plant height and biomass were moderate upon visual inspection (Fig. 2). The infectivity rate, as determined by the presence of visual chlorosis or necrosis symptoms on the diseased plants, for BSMV, BMV, SYBV, WSMV, and FoMV infections of $B$. distachyon was $100 \%$, while PMV+SPMV and MMMV infections resulted in 95 and $90 \%$ infectivity rates, respectively.

To enable comparative analyses of antiviral responses between $\mathrm{C}_{3}$ and $\mathrm{C}_{4}$ grass types, we tested if $S$. viridis (green foxtail millet) would be a likely candidate. $S$. viridis plants at the two- to three-leaf stage were inoculated with the seven viruses that infected B. distachyon (Fig. 2; Table 1). The disease progression was monitored at the same three stages described above. Surprisingly, all viruses also infected $S$. viridis and caused similar symptoms of chlorosis, necrosis, and reduced plant height and biomass (Fig. 2), although with different dynamics and infectivity rates. Similar to the responses in B. distachyon, BMV infection of S. viridis was $100 \%$ and the infected plants died shortly after stage II, while SYBV-infected plants showed mild to moderate chlorosis symptoms in stage II that became more prominent by stage III. The infectivity rate of SYBV, however, varied between the two hosts. SYBV infected $100 \%$ of $B$. distachyon plants, yet only $9 \%$ of $S$. viridis plants showed symptoms typical of an infection. BSMV-, MMMV-, WSMV-, and FoMV-infected $S$. viridis plants survived until stage III with 100, 100, 92, and $100 \%$ infectivity rates, respectively.

To confirm the presence of each virus in the symptomatic plants, immunoblotting analyses were performed (Fig. 3). All of the viral capsid proteins consistently accumulated in the upper noninoculated systemically infected leaves during disease progression, although some were below detectable levels in the inoculated leaves at stage I. Due to environmental variables, SPMV capsid protein (SPCP) accumulation in PMV+SPMV- infected B. distachyon was below detection by immunoblot assays in some stages of infection. For this, we also measured accumulation of SPMV RNA in the inoculated and upper noninoculated leaves, using reverse transcription-polymerase chain reaction (RT-PCR) with SPCP-specific primers. SPMV RNA consistently accumulated throughout the disease stages (Fig. 3A) and in all three B. distachyon PMV+SPMV replicates (Supplementary Fig. S2). Together, these results establish $B$. distachyon and $S$. viridis as compatible hosts for diverse grass viruses and reveal striking similarities in symptom induction by the seven viruses in the two grass types.

\section{Quantitative effects of grass virus infection on plant developmental and agronomic traits.}

Plant pathogens perturb host physiology, growth, and development, which negatively affect agronomic traits such as yield and biomass. Because the seven grass viruses used here infect diverse agronomic crops (Table 1) and cause significant crop losses, we determined the extent of these deleterious effects in $B$. distachyon and $S$. viridis. For this, we quantified agronomic parameters such as leaf length, tiller number, plant height, internode length, biomass, spikelet number, and spikelet weight of the virus-infected grasses. When compared with mock-inoculated plants, virus-infected plants had significantly smaller leaves, reduced tiller numbers, shorter internodes, shorter stature (plant height), and lower shoot weight (Fig. 4). These effects were observed in both B. distachyon and S. viridis and recapitulated the symptoms observed in their agronomic host plants. Although SYBV-infected B. distachyon plants, upon visual inspection, only exhibited mild chlorosis symptoms with no apparent effect on leaf length and plant height (Fig. 2), the plants had significantly shorter internodes, fewer tillers, and lower shoot weight (Fig. 4B, D, and E). These negative effects of SYBV were not significant in $S$. viridis, perhaps due to the delayed onset of symptoms and lower symptom induction (approximately 9\%), when compared with B. distachyon (approximately 100\%). WSMV- and FoMVinfected plants had shorter internodes and reduced height. Interestingly, WSMV- and FoMV-infected S. viridis plants developed an additional internode (Fig. 4I), as compared with mock-inoculated plants. Lastly, all virus infections were associated with decreased spikelet weights and inflorescence numbers that could impact seed yield in $S$. viridis. Because $B$. distachyon requires additional vernalization treatment of about 2 weeks to promote flowering, and by then, most viruses (BMV,

Table 1. Grass viruses used in the current study

\begin{tabular}{|c|c|c|c|c|c|}
\hline Virus $^{a}$ & Genus & Family & Genome $^{\text {b }}$ & Structure $^{b}$ & Host range $^{c}$ \\
\hline Panicum mosaic virus (PMV) & Panicovirus & Tombusviridae & Monopartite, ssRNA (+) & Icosahedral $(\mathrm{T}=3)$ & $\begin{array}{c}\text { Bd, Sv, foxtail, proso, pearl, } \\
\text { wheat, maize, switchgrass }\end{array}$ \\
\hline $\begin{array}{l}\text { Satellite panicum mosaic virus } \\
\text { (SPMV) }\end{array}$ & NA & NA & Monopartite, ssRNA (+) & Icosahedral $(\mathrm{T}=1)$ & $\begin{array}{c}\text { Bd, Sv, foxtail, proso, pearl, } \\
\text { wheat, maize, switchgrass }\end{array}$ \\
\hline Barley stripe mosaic virus (BSMV) & Hordeivirus & Virgaviridae & Tripartite, ssRNA (+) & Rigid rod & $\mathrm{Bd}, \mathrm{Sv}, \mathrm{Nb}$, barley, wheat, oat \\
\hline Brome mosaic virus (BMV) & Bromovirus & Bromoviridae & Tripartite, ssRNA (+) & Icosahedral $(\mathrm{T}=3)$ & $\begin{array}{l}\mathrm{Bd}, \mathrm{Sv}, \mathrm{Nb} \text {, foxtail, barley, } \\
\text { wheat, maize, oat }\end{array}$ \\
\hline Maize mild mottle virus (MMMV) & Unassigned & Unassigned & Monopartite, ssRNA (+) & Icosahedral $(\mathrm{T}=?)$ & $\begin{array}{l}\text { Bd, Sv, foxtail, pearl, maize, } \\
\text { wheat, barley, sorghum }\end{array}$ \\
\hline $\begin{array}{l}\text { Sorghum yellow banding virus } \\
\text { (SYBV) }\end{array}$ & Unassigned & Unassigned & $?$ & Icosahedral $(\mathrm{T}=?)$ & $\begin{array}{l}\text { Bd, } \mathrm{Sv}, \text { foxtail, proso, pearl, } \\
\text { maize, sorghum }\end{array}$ \\
\hline Wheat streak mosaic virus (WSMV) & Tritimovirus & Potyviridae & Monopartite, ssRNA (+) & Flexuous rod & Bd, Sv, wheat, maize, barley \\
\hline Foxtail mosaic virus (FoMV) & Potexvirus & Alphaflexiviridae & Monopartite, ssRNA (+) & Flexuous rod & $\begin{array}{l}\mathrm{Bd}, \mathrm{Sv}, \mathrm{Nb} \text {, proso, foxtail, } \\
\text { sorghum, barley, wheat, oat }\end{array}$ \\
\hline
\end{tabular}



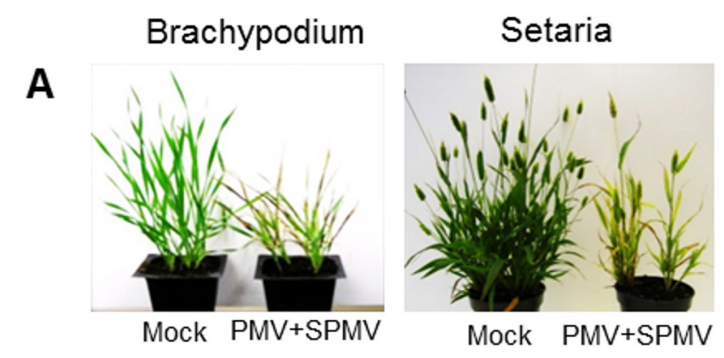

B
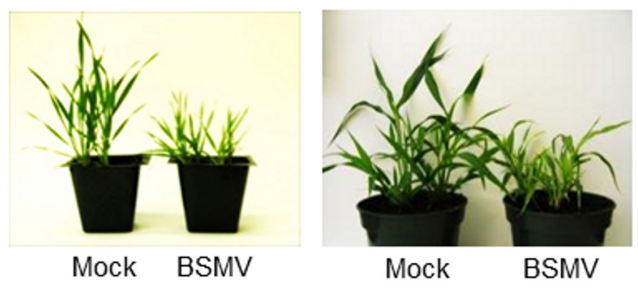

C
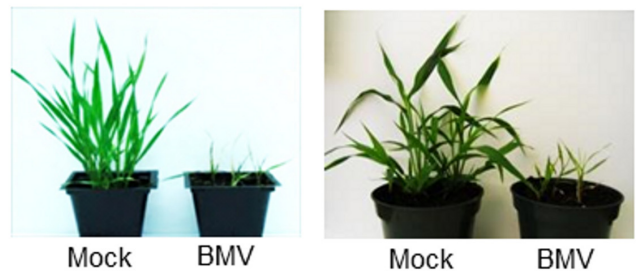

D
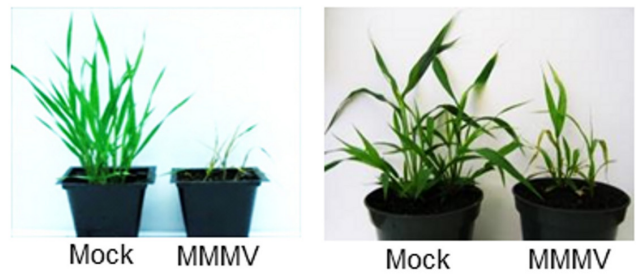

E
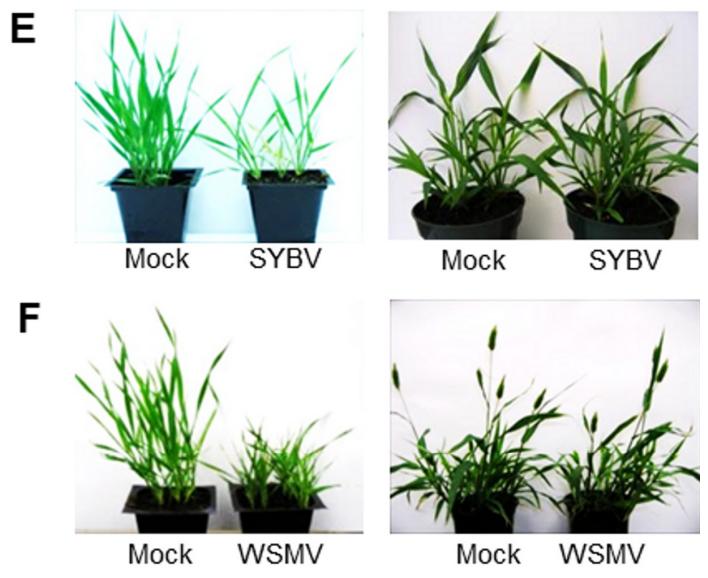

G
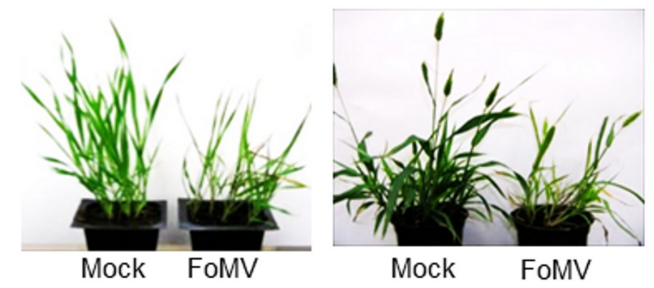

Fig. 2. Typical disease symptoms of virus-infected Brachypodium distachyon and Setaria viridis. A, Symptoms induced by Panicum mosaic virus (PMV) plus satellite PMV (PMV+SPMV), B, Barley stripe mosaic virus (BSMV), C, Brome mosaic virus (BMV), D, Maize mild mottle virus (MMMV), E, Sorghum yellow banding virus (SYBV), F, Wheat streak mosaic virus (WSMV), and G, Foxtail mosaic virus (FoMV) in B. distachyon and $S$. viridis at 21 days postinoculation. All viruses, with the exception of SYBV, caused prominent chlorosis and necrosis of leaves and severe stunting of plant height.
MMMV, WSMV, and FoMV) had killed the plants, we were unable to measure these parameters in B. distachyon. However, independent experiments with vernalized $B$. distachyon infected with PMV+SPMV showed drastic negative effects on seed set and inflorescence formation (Mandadi and Scholthof 2012), similar to those previously observed in millets (Scholthof 1999). Together, these experiments demonstrate that diverse viruses have similar negative impacts on agronomic traits in B. distachyon and $S$. viridis, recapitulating their effects on the field grass hosts.

\section{$\mathrm{C}_{3}$ antiviral defense hormone responses in $B$. distachyon.}

To analyze changes in plant defense hormone signaling triggered by the diverse grass viruses in $B$. distachyon, we assayed the expression patterns of multiple SA, JA, and ET signaling components during the seven grass virus infections. For this, we selected thirteen candidate defense marker genes in SA $(P R-1$, PR-3, PR-5, AOX1A, PAD4, and NPRI), JA (AOS, LOX2, FAD7, and $V S P 1)$ and ET (ERF1,ERF3, and ERF4) signaling, whose expression was significantly altered during PMV+SPMV infection in B. distachyon (Mandadi and Scholthof 2012). In preliminary RT-PCR analyses of a subset of virus-infected samples, we observed strong changes in the expression of several genes during infection (Supplementary Fig. S3). In order to quantify these differences, we performed quantitative (q)RT-PCR analyses and determined the temporal expression patterns of the thirteen markers in response to the seven grass virus infections in $B$. distachyon. Three independent biological replicates were used for the qRT-PCR analyses. The qRT-PCR expression data was normalized to levels of a constitutively expressed gene, UBIQUITIN18 (Hong et al. 2008), and was compared with the respective expression data from mock-inoculated plants. Consistent with our previous findings (Mandadi and Scholthof 2012), PMV+SPMV-infection in $B$. distachyon strongly induced expression of $P R-1$ (>20-fold), PR-3 (>threefold), PR-5 (>20fold), and $A O X 1 A$ ( $>100$-fold) as early as stage I (10 dpi), and expression remained higher throughout sampling times when compared with mock (Fig. 5A and H). Expression of PAD4, which functions upstream in SA signaling, was downregulated (>1.8-fold) (Fig. 5A), again consistent with our previous report. Expression of NPR1, a key modulator of SA-JA crosstalk in Arabidopsis, did not change significantly in PMV+SPMVinfected B. distachyon (Fig. 5A). In contrast to the SA signaling components, expression of genes in JA biosynthesis and signaling $(A O S, L O X 2, F A D 7$, and VSP1) and ET signaling (ERF1, $E R F 3$, and ERF4) were down-regulated during PMV+SPMV infection during stage I and, generally, remained lower throughout the disease progression (Fig. 5A and H). Expression patterns of the thirteen marker genes during BSMV, BMV, MMMV, and SYBV infection were strikingly similar to PMV+SPMV (Fig. $5 \mathrm{~B}$ to E). While WSMV- and FoMV-infected plants showed similar induction of SA components ( $P R-1$ and $P R-5$ genes) compared with the other viruses, the expression pattern of JA and ET components was different and lacked a clear trend of downregulation (Fig. 5F and G). Hierarchical clustering (HCL) analyses of the defense gene expression among the virus groups also revealed that the expression responses triggered by SYBV, BMV, BSMV, MMMV, and PMV+SPMV clustered together and were distant to WSMV and FoMV responses. Together, these results reveal that, although most viruses similarly induce SA components and reduce JA and ET components in $B$. distachyon, some viruses, like WSMV and FoMV, trigger unique outcomes.

$\mathrm{C}_{4}$ antiviral defense hormone responses in $\mathrm{S}$. viridis.

$\mathrm{C}_{4}$ photosynthetic pathways evolved independently at multiple times among the grasses and were accompanied by both ana- 
tomical and metabolic alterations to the cellular apparatus (Bennetzen et al. 2012; Grass Phylogeny Working Group II 2012). The influence of these specializations on $C_{4}$ defense hormone signaling pathways and $\mathrm{C}_{4}$ grass-virus interactions remain largely unknown. To this end, we analyzed the expression pattern of the thirteen defense signaling genes in SA, JA, and ET signaling in $S$. viridis (a $\mathrm{C}_{4}$ grass) in response to the seven virus infections (Table 1) and compared their expression dynamics to those occurring in B. distachyon ( $\mathrm{C}_{3}$ grass). S. viridis orthologs of the thirteen $B$. distachyon defense markers were identified using the peptide ortholog analysis tool at Phytozome (Goodstein et al. 2012). After preliminary RT-PCR analyses of a subset of virus-infected samples, we performed qRT-PCR analyses of three independent biological replicate samples of PMV+SPMV-, BSMV-, BMV-, MMMV-, SYBV-, WSMV-, and FoMV-infected $S$. viridis plants at different stages of infection.

Similar to the expression responses in B. distachyon, $\mathrm{PMV}+\mathrm{SPMV}$-infection in $S$. viridis induced expression of $P R-1$, $P R-5$, and $A O X 1 A$, while expression of PAD4 was suppressed (Fig. 6A and H). Expression of NPRl did not change significantly early in the infection (stages I and II), however, its expression was induced at stage III (Fig. 6A). Expression of JA signaling genes $A O S, L O X 2$, and FAD7 and an ET signaling component, ERF4, was consistently downregulated during

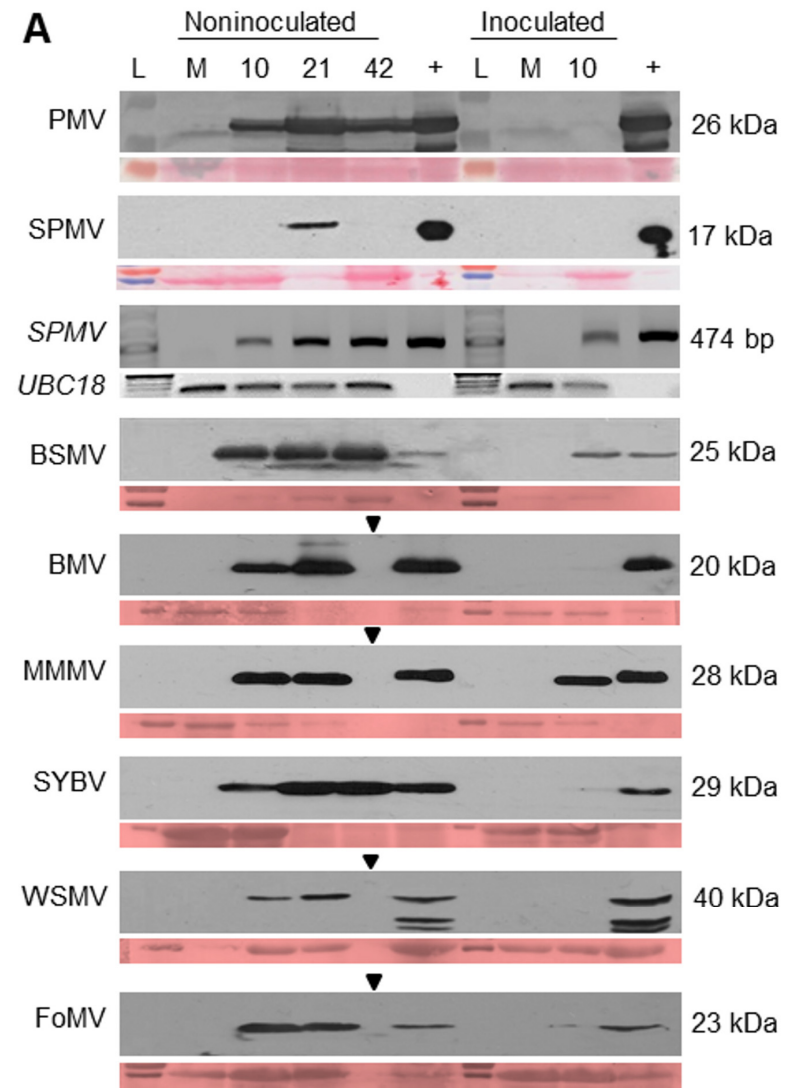

PMV+SPMV infection and paralleled the responses in B. distachyon (Fig. 6A). However, we also found divergent outcomes among $B$. distachyon and $S$. viridis defense gene responses. For example, in $B$. distachyon, expression of $P R-3$ was induced (>twofold), while expression of ERF1 and ERF3 was suppressed (>twofold) during PMV+SPMV infection (Fig. 5A). Conversely, in $S$. viridis expression of $P R-3$ was strongly suppressed (>20-fold), while expression of ERF1 and ERF3 was induced (>twofold) during PMV+SPMV infection (Fig. 6A). The opposing expression patterns of $P R-3, E R F 1$, and ERF3 during PMV+SPMV infection of $S$. viridis were also apparent in BSMV-, BMV-, MMMV-, and SYBV-infected S. viridis, although with varying degrees of fold change (Fig. 6A to E). Furthermore, WSMV and FoMV triggered unique responses in $S$. viridis that were distinct from the responses induced by the other viruses. WSMV- and FoMV-induced gene expression patterns clustered together in the HCL dendrogram (Fig. 7B); however, the clustering was less apparent compared with $B$. distachyon (Fig. 7A). Together, our results suggest that, in addition to some broad parallels among $B$. distachyon and $S$. viridis antiviral responses, such as upregulation of $P R-1, P R-5$, and $A O X 1 A$ (SA signaling) and downregulation of JA or ET components (AOS, $L O X 2, F A D 7$, and ERF4), there are also unique host-dependent and virus-specific effects on defense signaling.
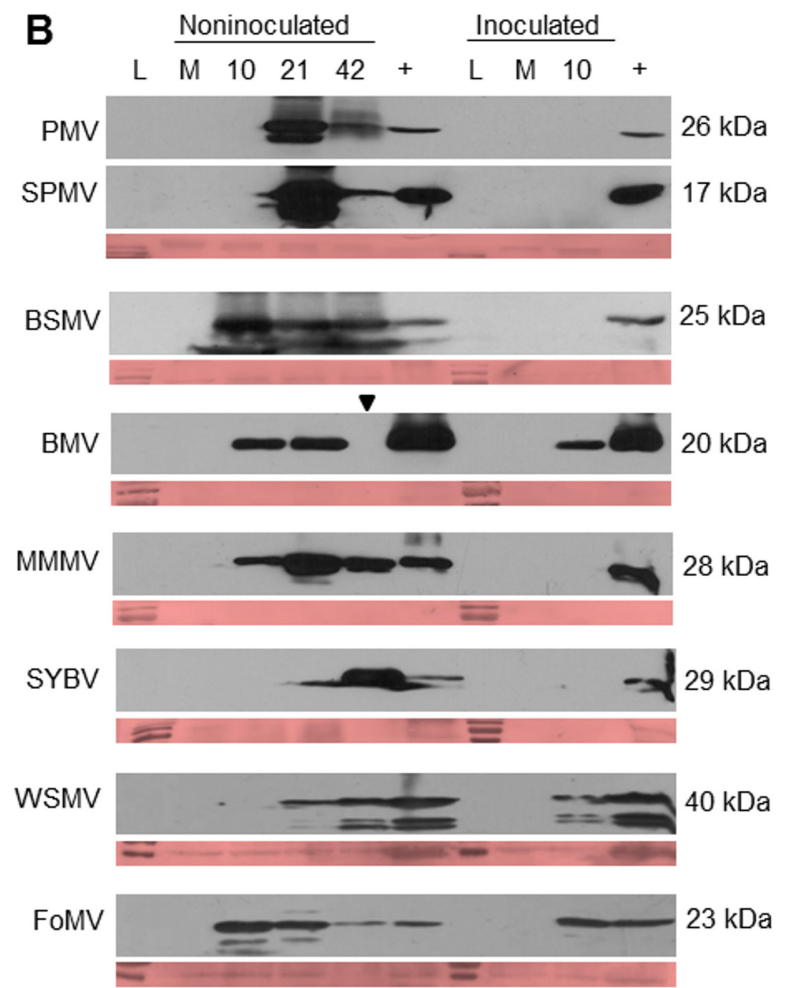

Fig. 3. Diagnosis of virus-infected A, Brachypodium distachyon and $\mathbf{B}$, Setaria viridis plants. Immunoblot analysis was performed for capsid protein detection at infection stages I (10 days postinoculation [dpi]), II (21 dpi), and III (42 dpi) of Panicum mosaic virus (PMV) plus its satellite virus (PMV+SPMV)-, Barley stripe mosaic virus (BSMV)-, Brome mosaic virus (BMV)-, Maize mild mottle virus (MMMV)-, Sorghum yellow banding virus (SYBV)-, Wheat streak mosaic virus (WSMV)- and Foxtail mosaic virus (FoMV)-infected B. distachyon and S. viridis. Lane L represents the protein molecular weight ladder, $\mathrm{M}$ represents the mock-inoculated sample, and + indicates a positive control, also used as the inoculum. The black arrowheads indicate instances when no samples were collected because infected plants did not survive through stage III. The Ponceau S-stained nitrocellulose membrane is shown below each immunoblot, to indicate approximately equal protein loading among the sample lanes. The molecular weight of each viral capsid protein is presented on the right side of each appropriate blot. Note: Because of high concentrations of some viral capsid proteins, particularly in S. viridis samples, the total protein loaded was diluted equally among the different samples, which resulted in weaker Ponceau S-staining of the membranes. Because SPMV capsid protein (SPCP) accumulation in B. distachyon was lower in the current experimental conditions, we also measured SPMV RNA in the inoculated and upper noninoculated leaves of $B$. distachyon PMV+SPMV-infected plants, using reverse transcription-polymerase chain reaction and with primers specific to the 474bp open reading frame for SPCP. Expression of B. distachyon UBIQUITIN18 (UBC18) was used to monitor template cDNA quantities used for the different samples and SPMV plasmid DNA was used as a positive control (+). 


\section{DISCUSSION}

Despite the significant agronomic relevance of studying grass antiviral defenses, much of the research to date has primarily focused on one or more of the epidemiology, pathogenicity, or virulence determinants of the individual viruses, largely due to the lack of an amenable monocot host pathosystem akin to Arabidopsis. Recent genome sequencing initiatives led to the rise of $B$. distachyon (a $\mathrm{C}_{3}$ grass) and $S$. viridis $\left(\mathrm{a}_{4}\right.$ grass) as model monocots for studying aspects of grass biology (Brutnell et al. 2010; International Brachypodium Initiative 2010). Importantly, these model grasses are evolutionarily
A

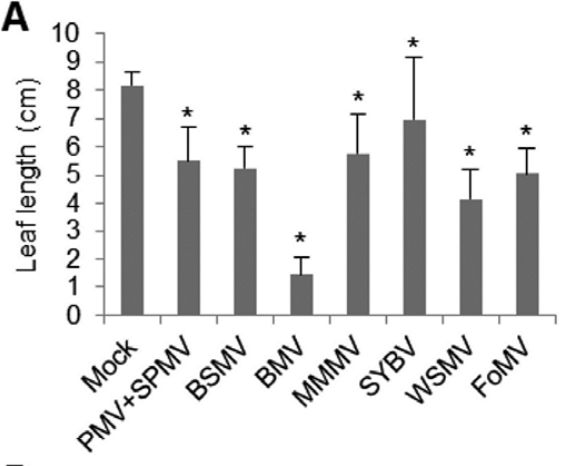

D

- Intemode \#1 - Intemode \#3 - Intemode \#5

\section{है⿴囗十)}

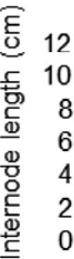

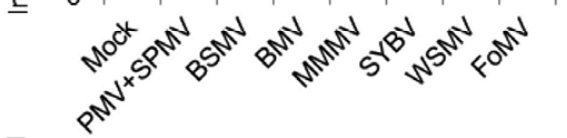

$\mathbf{F}$

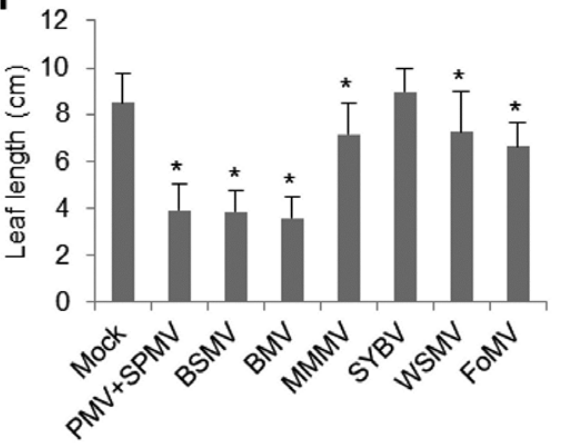

I

- Intemode \#1

- Intemode \#3

- Intemode \#5

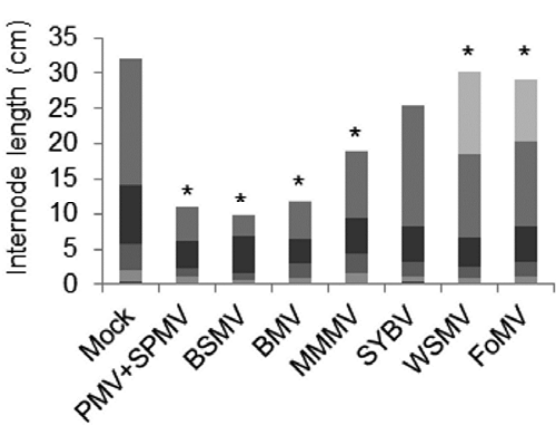

B

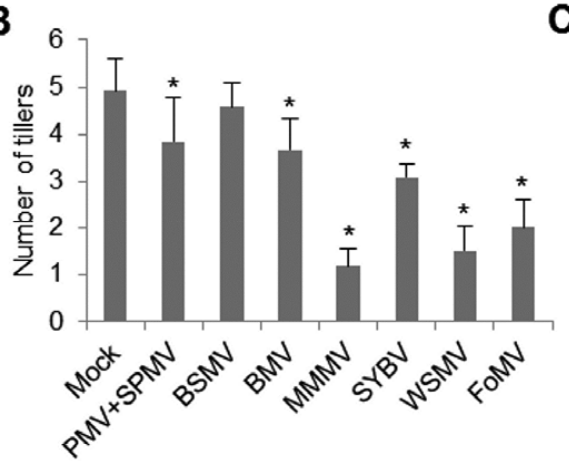

E 1.8

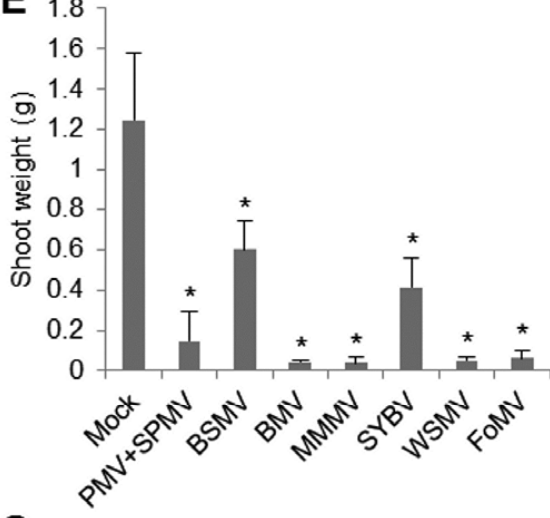

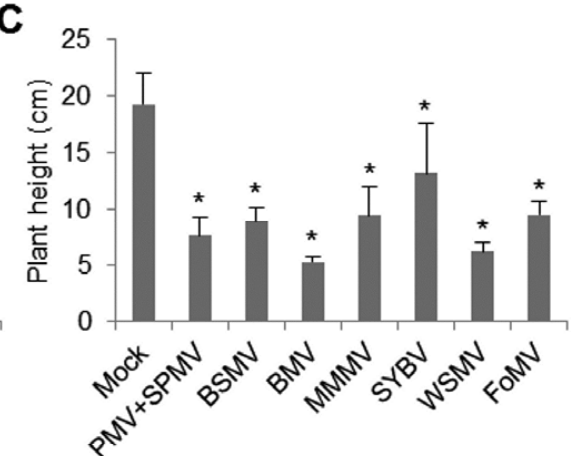

G

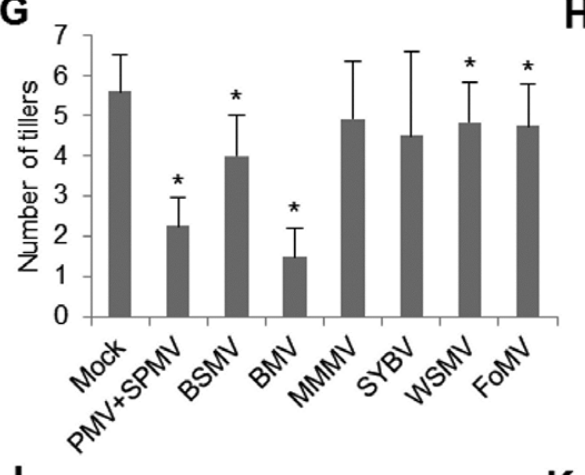

J

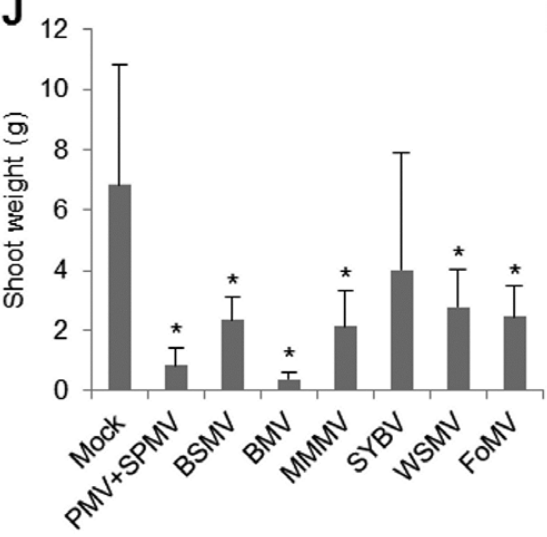

$\mathrm{H}$

K
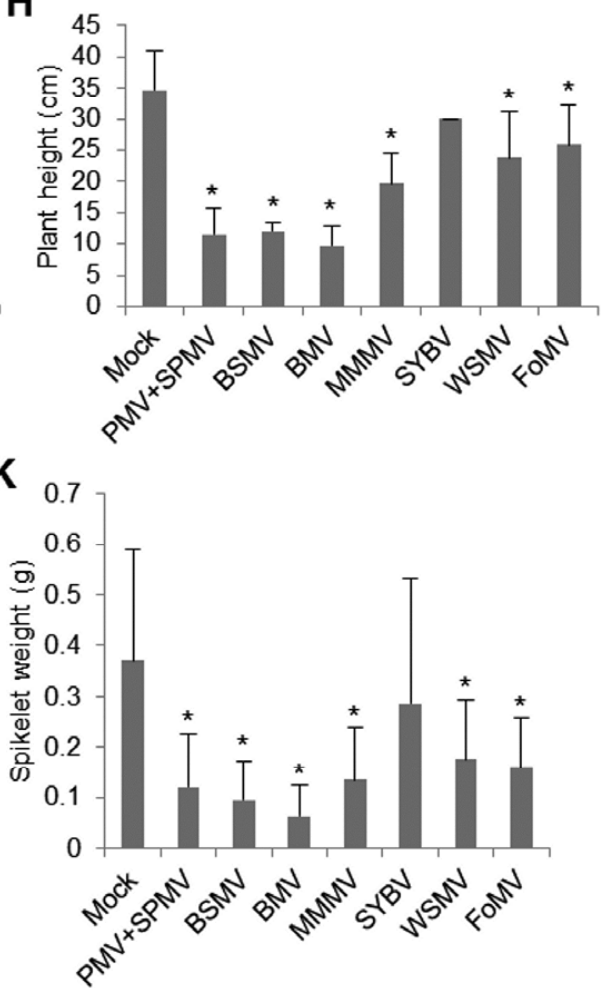

Fig. 4. Plant growth, development, and agronomic traits affected by virus infections. A through $\mathbf{E}$, All virus infections in Brachypodium distachyon and $\mathbf{F}$ through K, Setaria viridis, with the exception of Sorghum yellow banding virus (SYBV), significantly reduced leaf length (A and F), decreased tiller number (B and G), caused stunting (C and H), reduced internodal elongation (D and I), and decreased shoot weight (E and J) and inflorescence (spikelet) fresh weight $(\mathrm{K})$. The asterisks represent statistically significant changes as determined using Student's $t$-test ( $P$ value $\leq 0.05, n=3$ to 36 ). 
A
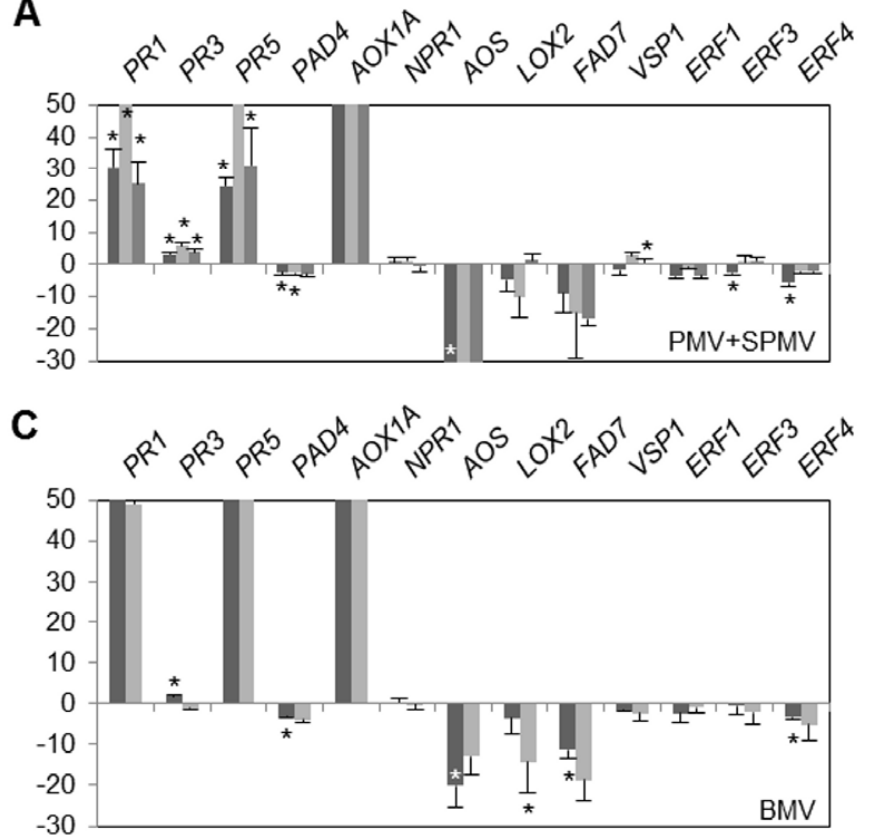

E

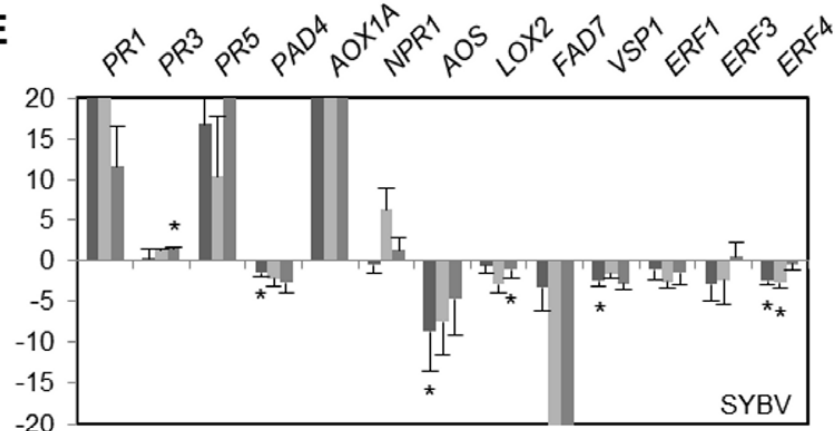

\section{G}

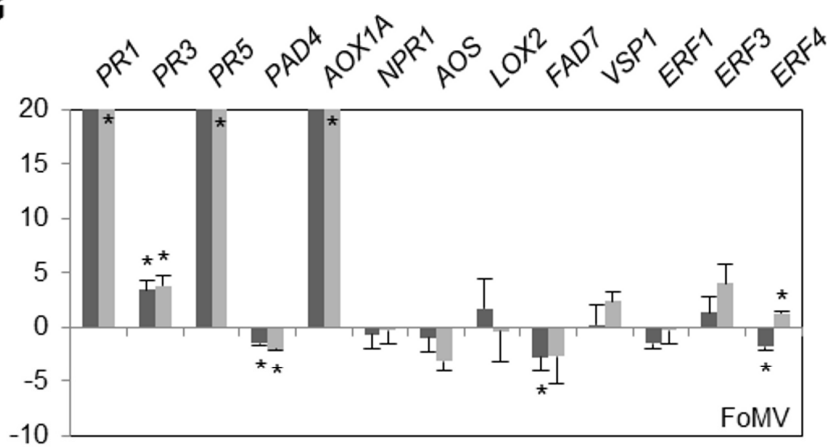

B

$\square 10 \mathrm{dpi}=21 \mathrm{dpi} \| 42 \mathrm{dpi}$

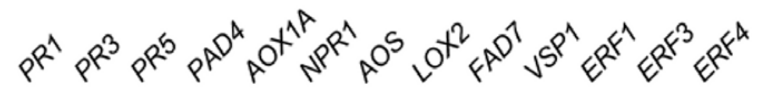
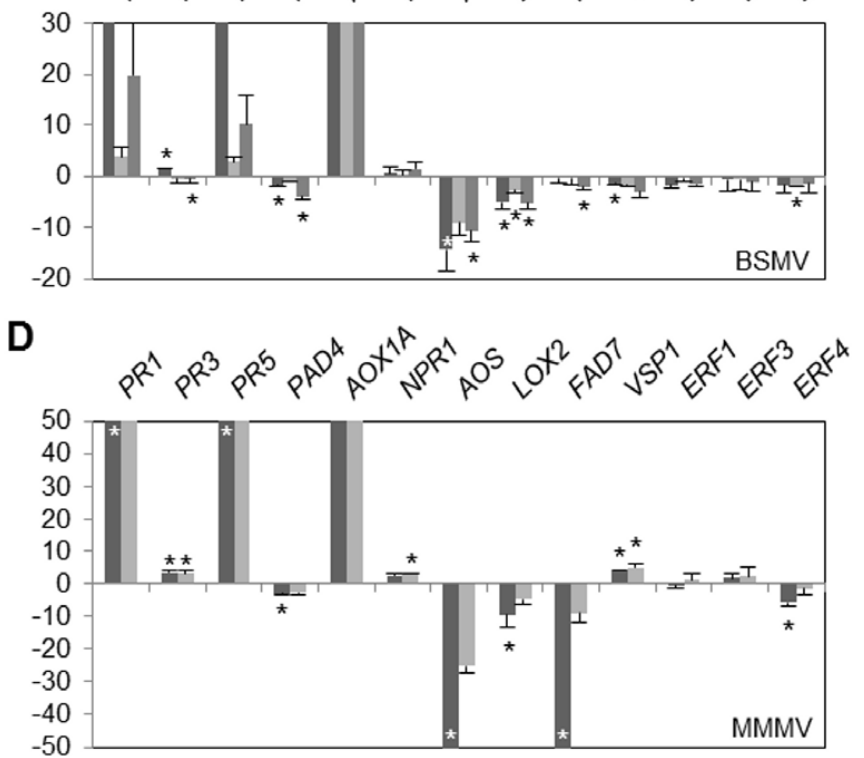

$\mathbf{F}$

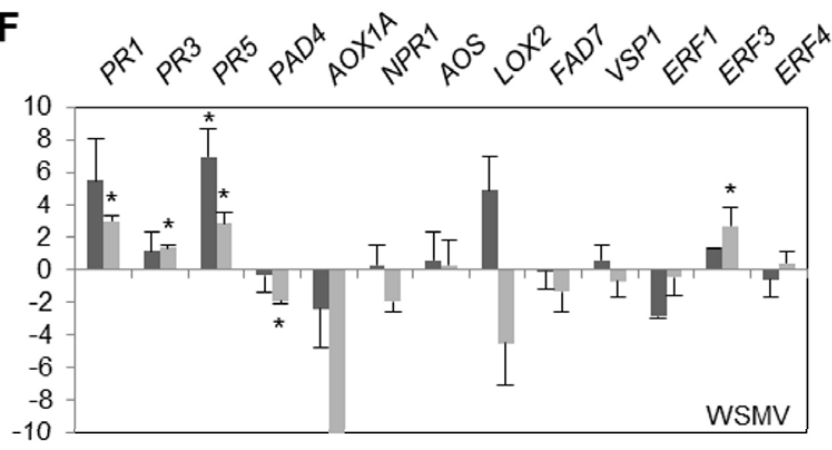

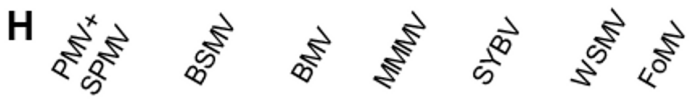

$102142 \underline{102142} \underline{1021} \underline{1021} \underline{102142} \underline{1021} \underline{1021} \mathrm{dpi}$

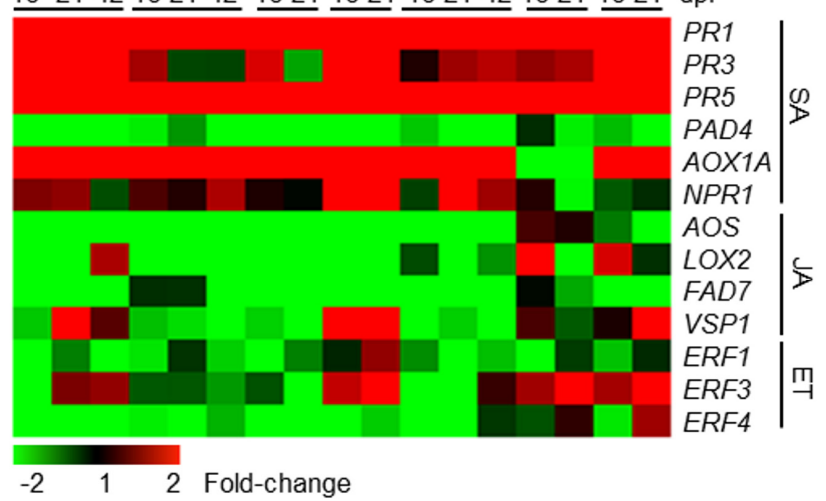

Fig. 5. Temporal expression profiles of salicylic acid (SA), jasmonic acid (JA), and ethylene (ET) signaling components during viral disease progression in Brachypodium distachyon. A, Plants infected with Panicum mosaic virus (PMV) plus satellite PMV (PMV+SPMV), B, Barley stripe mosaic virus (BSMV), C, Brome mosaic virus (BMV), D, Maize mild mottle virus (MMMV), E, Sorghum yellow banding virus (SYBV), F, Wheat streak mosaic virus (WSMV), and G, Foxtail mosaic virus (FoMV) were sampled at stages I (10 days postinoculation [dpi]), II (21 dpi), and III (42 dpi), and candidate gene expressions were analyzed by quantitative reverse transcription-polymerase chain reaction (qRT-PCR). The transcript level of UBIQUITIN18 was used to normalize the qRT-PCR data. Gene expression values in individual virus panels are the average of three independent biological replicates and are relative to mock. The error bars represent standard error of the three biological replicates. The asterisks represent statistically significant changes in gene expression as determined using Student's $t$-test $(P$ value $\leq 0.05)$. Expression values higher than the maximum set on the $y$ axis are trimmed for visualization of smaller fold changes. The missing timepoints were instances when infected plants did not survive through stage III, and thus, no samples were collected. H, The pseudocolored heat map represents defense gene expression during disease progression in virus-infected $B$. distachyon. The colors indicate fold change in gene expression; green for greater than or equal to twofold suppression and red for greater than or equal to twofold induction when compared with mock. 
A

$$
\square 10 \mathrm{dpi} \quad=21 \mathrm{dpi} \quad \square 2 \mathrm{dpi}
$$

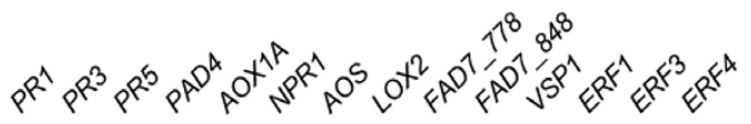

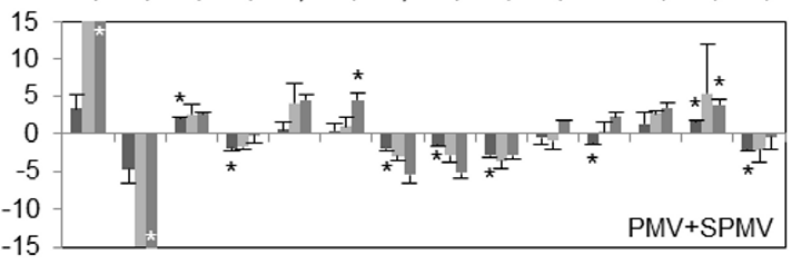

C

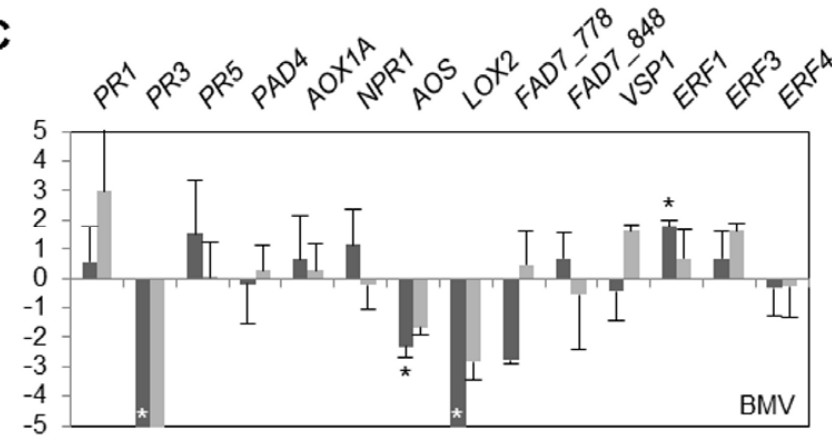

E

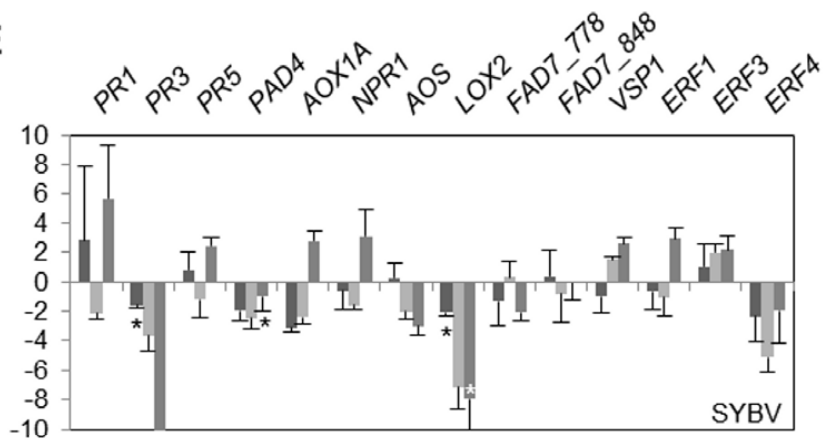

G

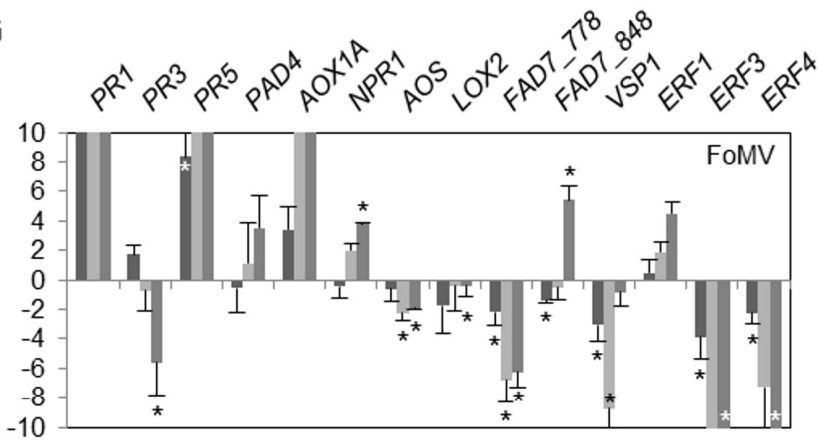

B

$\square 10 \mathrm{dpi}=21 \mathrm{dpi}=42 \mathrm{dpi}$

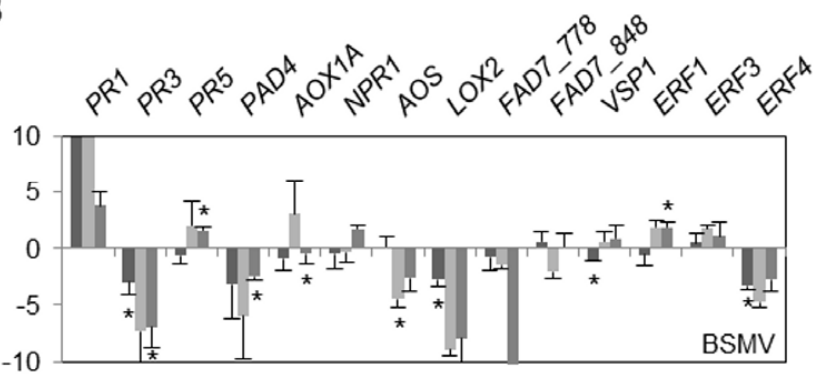

D

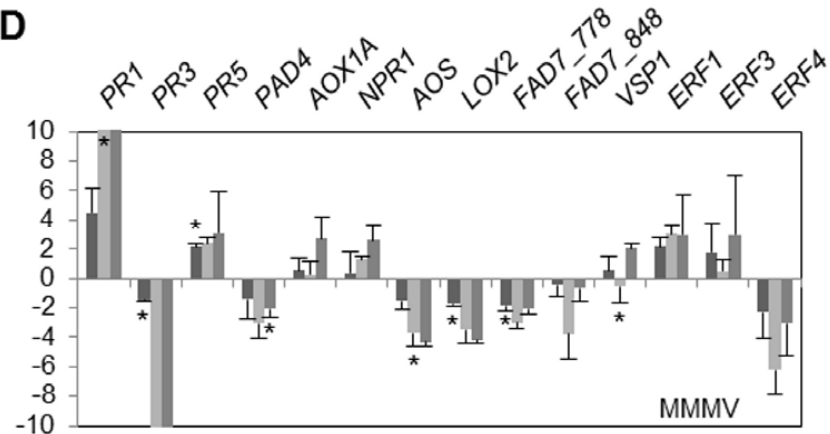

$\mathbf{F}$

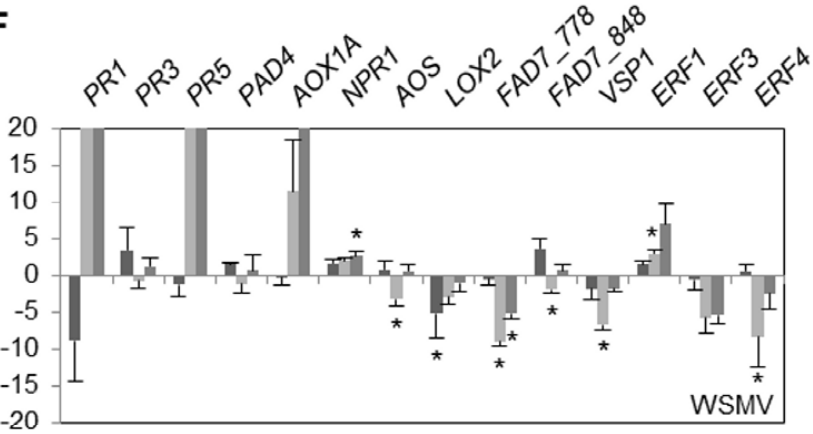

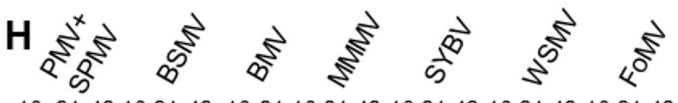

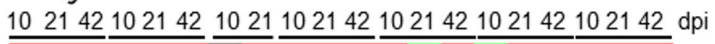

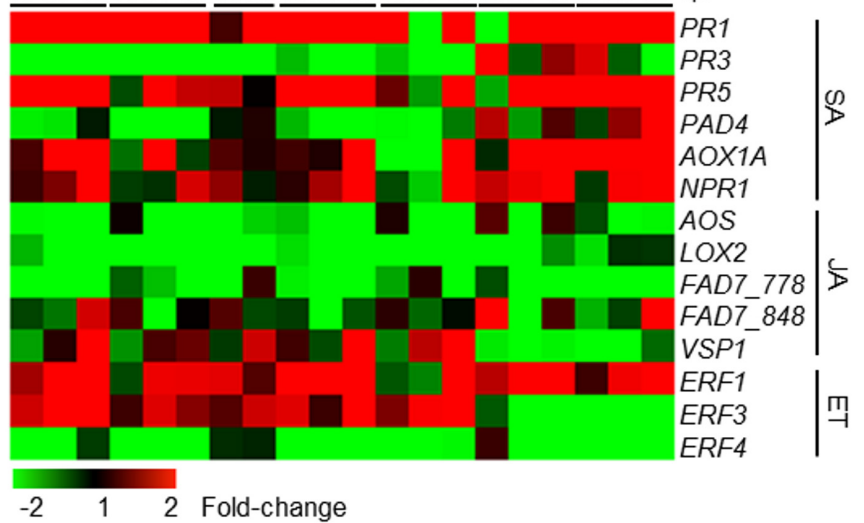

Fig. 6. Temporal expression profiles of salicylic acid (SA), jasmonic acid (JA), and ethylene (ET) signaling components during viral disease progression in Setaria viridis. A, Plants infected with Panicum mosaic virus (PMV) plus satellite PMV (PMV+SPMV), B, Barley stripe mosaic virus (BSMV), C, Brome mosaic virus (BMV), D, Maize mild mottle virus (MMMV), E, Sorghum yellow banding virus (SYBV), F, Wheat streak mosaic virus (WSMV), and G, Foxtail mosaic virus (FoMV) were sampled at stages I (10 days postinoculation [dpi]), II (21 dpi), and III (42 dpi) and were analyzed by (q) RT-PCR. The transcript level of UBIQUITIN18 was used to normalize the quantitative reverse transcription-polymerase chain reaction data. Gene expression values in individual virus panels are the average of three independent biological replicates and are relative to mock-inoculated plants. The error bars represent standard error of the three biological replicates. The asterisks indicate statistically significant changes in gene expression as determined using Student's $t$-test $(P$ value $\leq$ 0.05). Expression values higher than the maximum set on the $y$ axis are trimmed for visualization of smaller fold changes. The missing timepoints were instances when infected plants did not survive through stage III, and thus, no samples were collected. $\mathbf{H}$, The pseudocolored heat map represents defense gene expression during disease progression in virus-infected S. viridis plants. The colors indicate fold change in gene expression; green for greater than or equal to twofold suppression and red for greater than or equal to twofold induction when compared with mock. Note: The two $S$. viridis orthologs of BdFAD7 are referenced as FAD7_778 and FAD7_848. 
much closer to the agronomic grasses, having extensive genomic collinearity (Fig. 1) (Brutnell et al. 2010; International Brachypodium Initiative 2010). B. distachyon and $S$. viridis both share their last common ancestor with rice about 40 to 53 million years ago, when compared with the divergence of Arabidopsis and rice at almost 150 million years ago (Bennetzen et al. 2012; Brutnell et al. 2010; International Brachypodium Initiative 2010).

We recently demonstrated the utility of $B$. distachyon for the analysis of grass defense signaling pathways through genomewide transcriptome analyses of PMV- and PMV+SPMVinfected plants (Mandadi and Scholthof 2012). Here, we establish $B$. distachyon and $S$. viridis as amenable host platforms for seven positive-sense ssRNA viruses in diverse genera that are threats to several key grasses used for food, forage, turf, and biofuel needs (Table 1). The seven viruses induced typical chlorosis and necrosis symptoms on the infected grass shoots and caused significant loss of agronomically relevant traits in $B$. distachyon and $S$. viridis (Figs. 2 to 4; Table 1). Taking advantage of the fourteen host-virus combinations, we performed comparative analysis of $\mathrm{C}_{3}$ and $\mathrm{C}_{4}$ antiviral immune responses, pertaining to virus-triggered and hormone-mediated defenses, to uncover conserved as well as unique host-dependent and virus-specific grass antiviral defenses.

In plants, SA, JA, and ET are the major defense hormones that mediate immune responses against diverse bacteria, fungi, and viruses (An and Mou 2011; Verhage et al. 2010; Pieterse et al. 2012). These hormone signaling pathways often exhibit significant crosstalk with each other. SA and JA signaling pathways are usually antagonistic to each other (An and Mou 2011; Pieterse et al. 2012), although there are examples of synergism (Mur et al. 2006). Precursors of both SA and JA are found in plants, metazoans, bacteria, fungi, and algae (Brodhun and Feussner 2011; Gerwick 1994; Lee et al. 2008). Moreover, in metazoans, certain lipid-derived and jasmonatelike hormones such as prostaglandins are antagonized by acetylsalicylic acid (Thaler et al. 2012). However, the presence of conserved genes and molecules alone is not evidence for SA-
JA crosstalk. Thaler and associates (2012) recently reviewed SA-JA crosstalk among land plants based on published experiments to date. These experiments included genetic and biochemical analyses, measurement of the abundance of SA, JA, or SA/JA-derivatives, and SA or JA marker gene expression after either exogenous application of SA or JA, inducing biotic stress condition, or both. Through ancestral-state reconstructions, SA-JA crosstalk, although not demonstrated experimentally for many land plants, was suggested to have origins dating back to the split of gymnosperms and angiosperms (Thaler et al. 2012). However, the majority of studies used for these evolutionary reconstructions primarily pertain to dicot plants. Only four studies involved monocot plants (Thaler et al. 2012), which included maize and sorghum $\left(\mathrm{C}_{4}\right.$ plants $)$ and rice and barley $\left(\mathrm{C}_{3}\right.$ plants $)$. Among the four grasses, evidence for SAJA crosstalk was absent in maize (Engelberth et al. 2011) but present in sorghum, rice, and barley (Lee et al. 2004; Salzman et al. 2005; Weichert et al. 1999). To our knowledge, neither these nor other studies have determined whether SA-JA crosstalk occurs in response to diverse grass virus infections. We addressed this question here by analyzing defense marker gene expression in fourteen $B$. distachyon and $S$. viridis viral pathosystems. The general pattern of expression changes of grass genes in the SA, JA, and ET pathways is suggestive of SA-JA crosstalk and antagonism occurring during diverse virus infections in $B$. distachyon and $S$. viridis (Figs. 5 to 8). For example, we consistently found upregulation of SA components such as $P R-1, P R-5$, and $A O X 1 A$ and downregulation of JA components $A O S, L O X 2$, and FAD7 among the two grasses in most grass-virus infections (Figs. 5 and 6), and these components fell in distinct groups in the HCL dendrogram (Fig. 7).

In addition to the conserved responses, there are noticeable virus-specific and host-dependent effects between $B$. distachyon and $S$. viridis as well as among the virus types. For example, we found divergent expression patterns for $P R-3$ in $B$. distachyon and $S$. viridis. Expression of $P R-3$ was induced by the majority of virus infections in B. distachyon (Fig. 5), while its expression was strongly down-regulated by the same virus
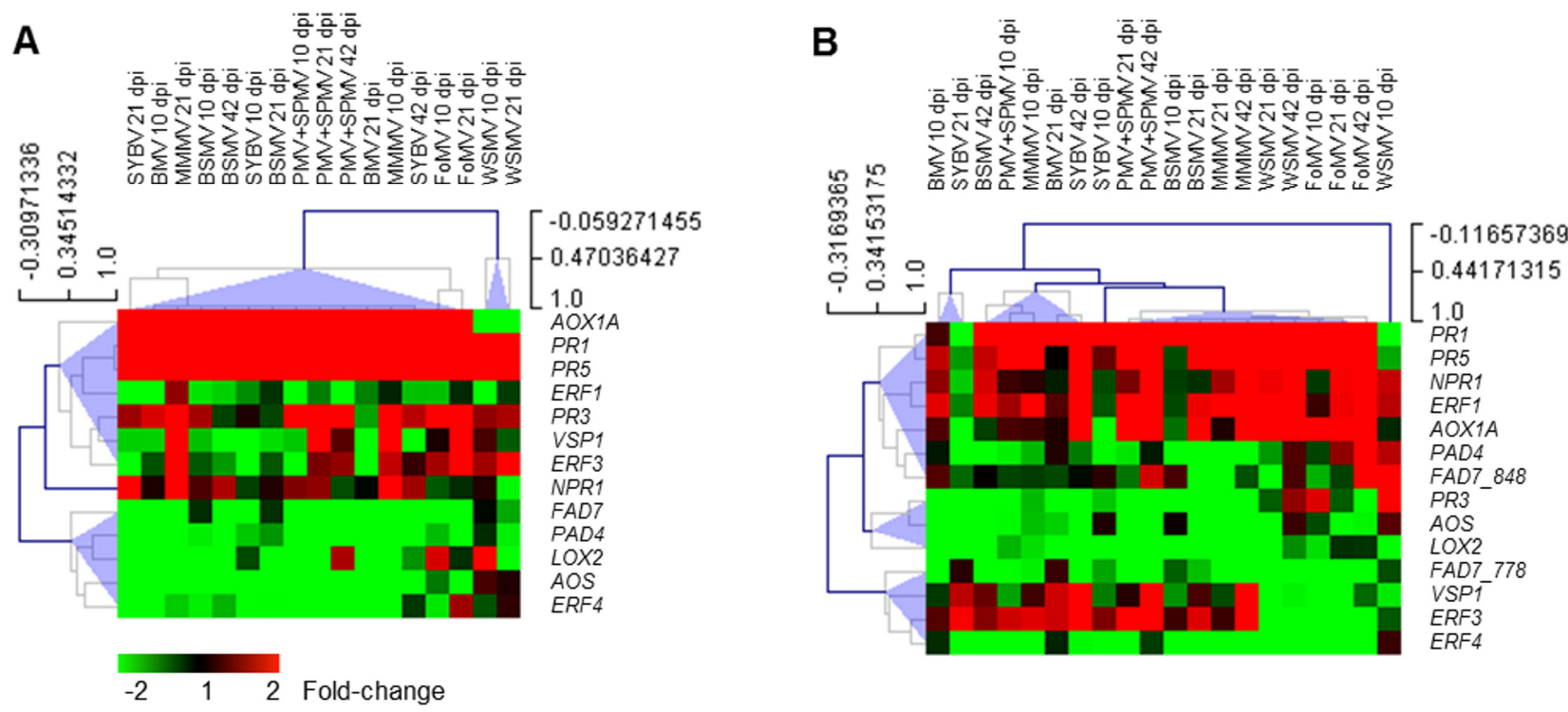

Fig. 7. Hierarchical clustering of antiviral immune responses. Expression of thirteen defense-hormone marker genes, determined using quantitative reverse transcription-polymerase chain reaction at infection stages I (10 days postinoculation [dpi]), II (21 dpi), and III (42 dpi) of Panicum mosaic virus (PMV) plus satellite PMV (PMV+SPMV)-, Barley stripe mosaic virus (BSMV)-, Brome mosaic virus (BMV)-, Maize mild mottle virus (MMMV)-, Sorghum yellow banding virus (SYBV)-, Wheat streak mosaic virus (WSMV)-, and Foxtail mosaic virus (FoMV)-infected A, Brachypodium distachyon and B, Setaria viridis. The hierarchical clustering was performed using the average linkage method and Pearson correlation metric. The node height scale is displayed beside the sample and the gene trees. The colors indicate fold change in gene expression: green indicates greater than or equal to twofold suppression and red greater than or equal to twofold induction when compared with mock. 
infections in $S$. viridis (Fig. 6). Similarly, expression of ERF1 and ERF3, which function in ET signaling, showed divergent expression patterns in $B$. distachyon and $S$. viridis (Figs. 5 and 6). Given that $C_{3}$ and $C_{4}$ grasses differ in their photosynthesis and metabolic carbon fixation pathways and leaf cellular anatomy (Brutnell et al. 2010), the observed differences in defense signaling components could be a consequence of $\mathrm{C}_{4}$ specializations that occurred in $S$. viridis. Alternatively or in addition, differences in promoter architecture of $B$. distachyon and $S$. viridis $P R-3, E R F 1$, and ERF3 or their target transcription factor activities, or both, could contribute to the observed opposing expression patterns.

In Arabidopsis, PAD4 functions upstream to NPR1 in SA signaling and mediates defense responses against fungi, bacteria, and viruses (Feys et al. 2001; Zhou et al. 1998; Zhu et al. 2011). For instance, AtPAD4 is required for HRT-mediated resistance against Turnip crinkle virus (TCV) (Chandra-Shekara et al. 2004). In our study, expression of PAD4 was consistently

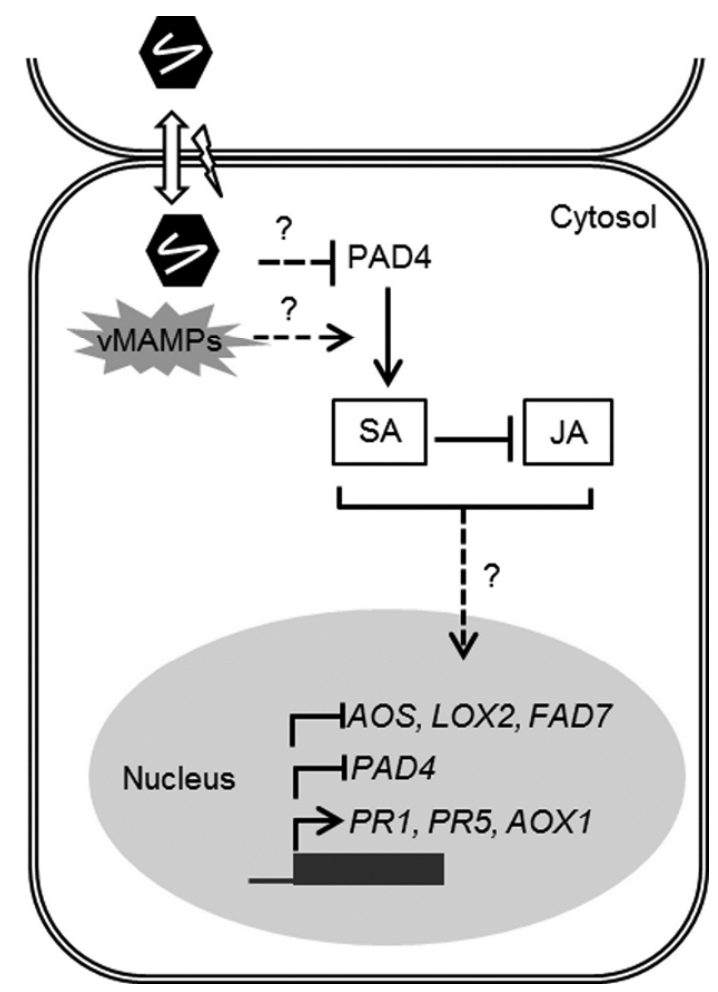

Fig. 8. Proposed model for hormone-mediated grass antiviral responses in Brachypodium distachyon and Setaria viridis. During virus infection, recognition of one or more of the conserved virion structures, capsid protein symmetry, and viral nucleic acid secondary structure, collectively known as viral microbe-associated molecular patterns (vMAMPs), by the host cellular receptors trigger immune responses (Allan et al. 2001; Chintakuntlawar et al., 2010; Hyde et al. 2014; Kendall et al. 2008; Parker et al. 2005).The defense hormone signals are transduced to the nucleus, perhaps by an NPR1-independent pathway, resulting in transcriptional reprogramming of defense-associated gene expression, although additional posttranscriptional modulations are a possibility. The relative abundance of $P A D 4$, an upstream regulator of the salicylic acid (SA) signaling pathway, was consistently lower during diverse compatible grass virus infections. However, the transcript levels of multiple downstream genes in the SA signaling pathway, including $P R 1, P R 5$, and $A O X 1$, are higher, while levels of jasmonic acid (JA) signaling pathway components AOS, LOX2, and $F A D 7$ are lower, providing evidence for putative SA-JA crosstalk during $\mathrm{C}_{3}$ and $\mathrm{C}_{4}$ compatible grass-virus interactions. The culmination of these immune responses leads to cell- or systemic necrosis-like symptoms and reflects the host's attempt to curtail virus infection. In a compatible infection, the virus triumphs over time, perhaps owing to robust virulence strategies, such as suppression of PAD4. Unknown components or putative outcomes are presented as dotted lines and a question mark (?). downregulated in multiple grass-virus interactions in B. distachyon and $S$. viridis, with the notable exception of WSMV and FoMV infection in S. viridis (Figs. 5 and 6). Viruses could evade or overcome host defenses by suppressing PAD4-mediated resistance, HR responses, or both. Thus, PAD4-suppression could be significant to disease establishment in compatible grass-virus interaction.

In Arabidopsis and rice, NPR1, a nucleo-cytoplasmic protein, mediates SA signaling and SA-JA crosstalk in response to bacterial and fungal infections (Chern et al. 2005; Dong 2004; Spoel et al. 2003; Yuan et al. 2007). Our analyses of the fourteen compatible grass-virus infections showed strong activation of SA signaling components, including $P R$ genes and $A O X 1 A$, in both $B$. distachyon and $S$. viridis as early as $10 \mathrm{dpi}$ (Figs. 5 and 6). However, the $P R$ gene induction did not correlate to changes in NPRl expression throughout the early stages of infection (10 and $21 \mathrm{dpi}$ ). NPRI expression was slightly upregulated at $42 \mathrm{dpi}$, more prominently in $S$. viridis than in $B$. distachyon. Together, these results suggest that virus-triggered induction of $P R$ gene expression, at least during the early stages of disease, may be independent of NPRI; however, $N P R 1$ may sustain SA signaling and $P R$ gene expression in later stages of infection. Because we cannot rule out changes occurring to the NPR1 protein level or activity from the current data, dependence of SA responses on NPR1 activity during the early stages of virus infection remains a possibility. Nevertheless, our observations support those noted for dicot virus-host interactions. For example, in Arabidopsis and tomato, resistance and immune response to multiple viruses such as TCV, Cucumber mosaic virus (CMV), and Oilseed rape mosaic virus are SA-dependent yet do not require NPR1 activity (Huang et al. 2005; Kachroo et al. 2000).

The mechanism of pathogen perception by the host defense machinery is highly complex, yet the key plant immune mechanisms to detect bacterial, fungal, and viral pathogens appear strikingly similar (Dodds and Rathjen 2010; Mandadi and Scholthof 2013; Schwessinger and Ronald 2012). Recognition of conserved pathogen- or microbe-associated molecular patterns (PAMPs or MAMPs) at the cell surface or pathogenencoded effector molecules inside the host cells triggers downstream defense signaling responses. Although viruses are not generally viewed as encoding MAMPs or effectors, analogous viral features do exist. Such virus-associated MAMPs, conserved viral capsid protein composition, viral nucleic-acid composition, or secondary structures (Chintakuntlawar et al. 2010; Hyde et al. 2014) may be perceived by the host defense machinery both outside and inside the plant cells, in order to trigger host defenses (Allan et al. 2001; Mandadi and Scholthof 2013). For example, exogenous application of Tobacco mosaic virus (TMV, a rigid rod tobamovirus) virions or isolated capsid protein outside of the tobacco leaf epidermis elicits a rapid intracellular oxidative burst, typically within a few seconds of application (Allan et al. 2001). This response is also triggered by related tobamoviruses with common host ranges, such as TMV and the TMV Ob strain, but not by an unrelated virus, CMV (Allan et al. 2001). Our analysis here revealed WSMV and FoMV triggered distinct changes in defense signaling components in B. distachyon and $S$. viridis, when compared with the other viruses (Figs. 5 to 7). A noticeable feature of WSMV and FoMV is that they both form similar flexible filamentous shape virions with conserved capsid protein folds and helical symmetries that are distinct from icosahedral or rigidrod virions (French and Stenger 2004; Kendall et al. 2008; Robertson and French 2004; Parker et al. 2005). It is possible that these distinct virion structural features of WSMV and FoMV contribute to the unique defense responses elicited in the infected plants (Fig. 8) (Mandadi and Scholthof 2013). 
Alternatively or in addition, differences in WSMV and FoMV replication, movement, or unique interactions with host components in $B$. distachyon and $S$. viridis compared with the other viruses, singly or in combination, could trigger unique host defense responses.

Together, through establishing and extending $B$. distachyon and $S$. viridis as host platforms for studying seven destructive monocot-infecting viral pathogens, this comparative analysis bridges some of the knowledge gaps that exist in the study of grass antiviral defenses, particularly relating to defense hormone-mediated responses. Our study uncovered multiple conserved as well as unique virus-specific and host-dependent defense signaling responses triggered during compatible grass virus infections and provides the first framework of SA, JA, and ET signaling components modulated during diverse $\mathrm{C}_{3}$ and $\mathrm{C}_{4}$ grass-virus interactions.

\section{MATERIALS AND METHODS}

\section{Plant growth conditions.}

Brachypodium distachyon (Bd21-3) and Setaria viridis (A10) were planted in $2 \times 3$-in. pots (BWI Companies) and 4-in. diameter pots, respectively, with Redi-Earth soil (Sungrow Horticulture). Seeds were stratified at $4{ }^{\circ} \mathrm{C}$ for 7 to 10 days in the dark. Subsequently, pots were transferred into growth chambers with diurnal cycles of $14 \mathrm{~h}$ light $\left(21^{\circ} \mathrm{C}\right)$ and $10 \mathrm{~h}$ dark $\left(18^{\circ} \mathrm{C}\right)$. Light intensity in the growth chamber was set to 250 to $300 \mu \mathrm{mol} / \mathrm{m}^{2} \mathrm{~s}$.

\section{Phylogenetic analyses.}

A phylogenetic species tree of $\mathrm{C}_{3}$ and $\mathrm{C}_{4}$ grasses (B. distachyon, barley, wheat, rice, foxtail millet $[S$. italica $]$, switchgrass, maize, sorghum, and sugarcane), and a dicot, Arabidopsis, was constructed using multiple sequence alignment (MSA) of an approximately 1,000-amino acid long concatenated super sequence corresponding to six conserved proteins: SAM decarboxylase, glyceraldehyde-3-phosphate dehydrogenase, chlorophyll a/b-binding protein P26, catalase, $\alpha$-tubulin, and heatshock protein 70 of the respective species (Vogel et al. 2006). Concatenation maximizes power to infer more accurate trees and is a common procedure to build species trees (Gadagkar et al. 2005; Vogel 2006). MSA was performed with the concatenated sequences using ClustalX2 (Larkin et al. 2007), and the resulting neighbor-joining tree was generated using the interactive tree of life (iTOL) tool (Letunic and Bork 2007). Bootstrapping with 1,000 replicates was performed to indicate confidence values for the different clades. Arabidopsis was used as an out-group for the grasses and as the reference dicot.

\section{Plant infections, sampling, virus inoculum, and in vitro transcription.}

$B$. distachyon and $S$. viridis plants were rub-inoculated at the two- to three-leaf stage with virus inoculum corresponding to BSMV (strain ND18), BMV (strain M1), MMMV, SYBV, WSMV (strain Sidney 81), and FoMV (strain H93). To avoid accumulation of SPMV defective interfering RNAs (Qiu and Scholthof 2000, 2001), in vitro-synthesized infectious RNA transcripts were used directly for PMV+SPMV infections. All rub-inoculated plants were stored in the dark with humid conditions overnight and were then transferred to growth chambers. Leaf tissue was collected from three individual plants at 10, 21, and 42 dpi. The infections were repeated three times independently, and the three replicate samples collected were used for further analyses.

For preparing BSMV, BMV, MMMV, SYBV, WSMV, and FoMV virus inoculum, infectious tissue that tested positive by immunoblotting was ground in virus inoculation buffer $(0.05 \mathrm{M}$
$\mathrm{KH}_{2} \mathrm{PO}_{4}, 1 \%$ celite) in a $1: 10$ (wt/vol) ratio and was subsequently used to rub-inoculate plants. Original BSMV infectious plant sap was produced by rub-inoculating healthy $B$. distachyon plants with in vitro-synthesized infectious BSMV transcripts (Petty et al. 1989). BSMV $\alpha, \beta$, and $\gamma$ plasmid genomes were linearized with $M l u \mathrm{I}$, SpeI, and MluI, respectively, and were used as templates for in vitro transcription using T7 RNA polymerase (Fermentas), according to manufacturer's instructions. BSMV transcripts were capped in vitro, using $\mathrm{m}^{7} \mathrm{G}\left(5^{\prime}\right) \mathrm{ppp}\left(5^{\prime}\right) \mathrm{G}$ cap analog (Life Technologies). Equal amounts of BSMV $\alpha, \beta$, and $\gamma(1: 1: 1)$ RNAs were mixed with RNA inoculation buffer $\left(0.05 \mathrm{M} \mathrm{KH}_{2} \mathrm{PO}_{4}, 50 \mathrm{mM}\right.$ glycine, $\mathrm{pH}$ $9.0,1 \%$ bentonite, $1 \%$ celite) and were used to rub-inoculate plants.

For preparing PMV and SPMV infectious transcripts, the respective plasmid genomes were linearized with EcoICRI and $B g l \mathrm{II}$, and were used as templates for in vitro transcription using T7 RNA polymerase. Subsequently, equal amounts of PMV and SPMV (1:1) transcripts were mixed in RNA inoculation buffer and used to rub-inoculate plants.

\section{Virus diagnosis, protein extraction, immunoblotting, and RT-PCR.}

Equal amounts of tissue samples were homogenized in $5 \times$ Laemmli sodium dodecyl sulfate (SDS) protein extraction buffer in 1.5-ml Eppendorf tubes on ice. The extracts were then boiled for $5 \mathrm{~min}$ and were centrifuged at $12,000 \times g$ for 5 min using a microcentrifuge.. The supernatant, containing the total protein extract, was subjected to electrophoresis for $1.5 \mathrm{~h}$ at 120 volts on $12.5 \%$ polyacrylamide-SDS gels. The electrophoresed proteins were transferred onto nitrocellulose membrane (BioRad) at $300 \mathrm{~mA}$ for $1.5 \mathrm{~h}$. Following transfer, membranes were stained with Ponceau $\mathrm{S}$ dye to visualize transfer efficiency and were washed with water to remove the Ponceau $\mathrm{S}$, and then, were blocked with $5 \%$ milk in $1 \times$ Tris-buffered saline (TBS) (0.2 M NaCl, $50 \mathrm{mM}$ Tris, $\mathrm{pH}$ 7.4) with $0.05 \%$ Tween-20 (TBST) solution for $1 \mathrm{~h}$ at room temperature, followed by primary antibody incubation with either anti-PMV (1:5,000), anti-SPMV (1:2,000), anti-BSMV $(1: 5,000)$, antiBMV (1:10,000), anti-MMMV (1:5,000), anti-SYBV (1:5,000), anti-WSMV $(1: 2,000)$, or anti-FoMV $(1: 2,000)$ capsid proteins. All antibodies were produced in rabbit except antiBSMV, which was produced in mouse. All membranes were washed three times for $5 \mathrm{~min}$ each with TBST. For BSMV, BMV, MMMV, SYBV, WSMV, and FoMV samples, membranes were incubated with horseradish peroxidase-conjugated goat antirabbit (Thermo Scientific) or antimouse (Rockland) secondary antibody $(1: 10,000)$ for $1 \mathrm{~h}$ at room temperature, and then, were washed twice in TBST for $5 \mathrm{~min}$, followed by $1 \times$ TBS for $5 \mathrm{~min}$. Visualization of the proteins was performed using SuperSignal West Pico (Pierce) or ECL Prime (Amersham) chemiluminescence detection reagents and X-ray film (Agfa).

For PMV+SPMV samples, after primary antibody incubation, membranes were washed as described above and were incubated with secondary alkaline phosphatase-conjugated goat antirabbit (Sigma) antibody $(1: 2,000)$ for $1 \mathrm{~h}$ at room temperature. Membranes were subsequently washed twice in TBST for $5 \mathrm{~min}$, followed by $1 \times$ TBS for $5 \mathrm{~min}$. Chromageneic detection was performed by addition of nitroblue tetrazolium and 5-bromo-4-chloro-3-indolylphosphate to visualize the capsid proteins. SPMV accumulation in $B$. distachyon is sensitive to variations in environmental factors, such as light intensity, temperature, and day length (Mandadi and Scholthof 2012). Because SPMV capsid protein detection using immunoblot assays was weaker in current experimental conditions in certain stages of infection, we also measured SPMV RNA in the 
inoculated and upper noninoculated leaves of PMV+SPMVinfected $B$. distachyon using RT-PCR with primers specific to the SPMV capsid protein open reading frame (forward primer: 5'-ATGGCTCCTAAGCGTTCCA-3'; reverse primer: 5'-TTAT GAAGACTGAAGCTCGC-3'). SPMV RNA was consistently detectable in the inoculated leaves and its abundance accumulated throughout disease progression in the upper noninoculated leaves (Fig. 3A). The presence and accumulation of SPMV was similar in all three $B$. distachyon $\mathrm{PMV}+\mathrm{SPMV}$ replicate samples and was further validated by performing SPMV bioassays (data not shown).

RNA isolation, quantitative qRT-PCR, and HCL analyses.

Total RNA from three independent biological replicates was extracted from plant tissue and was Dnase I-treated, using the Direct-zol RNA MiniPrep kit (Zymo Research), following the manufacturer's protocol. The quality and the quantity of the RNA was determined using Nano-Drop absorption values $(260 / 280=1.9$ to 2.1$)$, and its visual integrity was determined by electrophoresis on a $1 \%$ agarose gel stained with ethidium bromide. Two micrograms of total RNA was used for firststrand cDNA synthesis, using SuperScript III reverse transcriptase (Invitrogen) following the manufacturer's protocol. For qRT-PCR analysis, the ABI 7500 Fast system (Applied Biosystems, Life Technologies) was used with SYBR Select master mix (Applied Biosystems, Life Technologies).

B. distachyon defense marker genes in SA, JA, and ET pathways were selected based on BLAST and peptide ortholog analysis (Goodstein et al. 2012) and phylogenetic analyses (Mandadi and Scholthof 2012). To identify S. viridis orthologs of candidate $B$. distachyon genes, we used the peptide homo$\log (\mathrm{PH})$ tool available through Phytozome (Goodstein et al. 2012) and searched against the annotated genome of its closest domesticated relative, $S$. italica (foxtail millet). $S$. viridis and $S$. italica genomes are highly syntenic, with little difference among the gene sequences as determined by Bennetzen and associates (2012). Further, the PH tool employs "all-against-all Smith-Waterman alignment" (Smith and Waterman 1981), which is considered superior to BLAST- or FASTA-based alignments for recovery of orthologous peptides to a query sequence (Pearson 1991; Shpaer et al. 1996). Genes that were difficult to call as direct orthologs or that had multiple homo$\log$ s within $B$. distachyon and $S$. viridis are indicated as "-like". For example, $S$. viridis has two FAD7-like genes (referred as $F A D 7$ 778 and FAD7_848) with close similarity to BdFAD7 (Supplementary Table S2) and were both included in the study. All primers were verified for specific matches in the $S$. viridis raw sequence libraries using SRA-BLAST analyses and were further tested by RT-PCR. Primer sequences without significant BLAST hits and those that did not produce a specific RTPCR amplicon were eliminated from the analyses. Of the fifteen $S$. viridis genes chosen initially for the study, only one gene homolog of the two AOXIA-like genes, Si010566m, did not pass the BLAST and RT-PCR tests and was removed from the study.

All gene-specific primers used for qRT-PCR were designed using QuantPrime (Arvidsson et al. 2008; Supplementary Tables $\mathrm{S} 1$ and S2). With the exception of PAD4 (Si026081m), all genes have only one annotated primary transcript. The primer sets were tested for specificity by separating the resulting RT-PCR products on $1 \%$ agarose gels via electrophoresis as well as by analyzing the dissociation curves after the qRT-PCR (Supplementary Fig. S4). Expression of UBIQUITIN18 (Bradi4g00660) was used for normalization. The fold changes in gene expression were calculated following the ${ }^{\Delta \Delta} \mathrm{C}_{\mathrm{T}}$ method (Livak and Schmittgen 2001) and are presented as relative to mock-inoculated plants that are set to 1 . Student's $t$-test was used to deter- mine statistical significances. Fold changes in expressions were also represented as pseudocolored heat maps using the Multiexperiment Viewer (MeV) (Saeed et al. 2003). The temporal fold changes in gene expression are also provided in Supplementary Table S3. To determine correlated expression patterns among the gene and virus groups, HCL analysis was performed with the MeV HCL tool using the average linkagemethod and Pearson correlation metric. The node height scale was adjusted to display the major gene- and virus-clusters.

\section{ACKNOWLEDGMENTS}

We thank A. O. Jackson (University of California, Berkeley), X. Wang (Virginia Tech), and D. Seifers and J. Ackerman (Kansas State University) for their generous gifts of BSMV, BMV, WSMV, and FoMV constructs, antibodies, and inoculum for our virus studies. We appreciate the helpful advice and critical comments provided by $\mathrm{H}$. Scholthof and $\mathrm{C}$. Lyons (Texas A\&M University) during the manuscript preparation. We also thank A. Doust (Oklahoma State University) for S. viridis (A10) seeds. This study was supported by funds from The Norman Hackerman Advanced Research Program (000517-0002-2009) grant awarded to K.-B. G. Scholthof and undergraduate research fellowships from the American Society of Plant Biologists (SURF), American Society for Microbiology (URF), and Texas A\&M University (BURS) awarded to J. D. Pyle. K. K. Mandadi, J. D. Pyle, and K.-B. G. Scholthof designed the research. K. K. Mandadi and J. D. Pyle performed the experiments. K. K. Mandadi, J. D. Pyle, and K.-B. G. Scholthof analyzed data and wrote the manuscript.

\section{LITERATURE CITED}

Albar, L., Bangratz-Reyser, M., Hébrard, E., Ndjiondjop, M.-N., Jones, M., and Ghesquière, A. 2006. Mutations in the eIF(iso)4G translation initiation factor confer high resistance of rice to Rice yellow mottle virus. Plant J. 47:417-426.

Allan, A. C., Lapidot, M., Culver, J. N., and Fluhr, R. 2001. An early Tobacco mosaic virus-induced oxidative burst in tobacco indicates extracellular perception of the virus coat protein. Plant Physiol. 126:97-108.

Alvarado, V. Y., and Scholthof, H. B. 2009. Plant responses against invasive nucleic acids: RNA silencing and its suppression by plant viral pathogens. Sem. Cell Dev. Biol. 20:1032-1040.

An, C., and Mou, Z. 2011. Salicylic acid and its function in plant immunity. J. Integ. Plant Biol. 53:412-428.

Arvidsson, S., Kwasniewski, M., Riaño-Pachón, D. M., and Mueller-Roeber, B. 2008. QuantPrime: A flexible tool for reliable high-throughput primer design for quantitative PCR. BMC Bioinformatics 9:465.

Ascencio-Ibáñez, J. T., Sozzani, R., Lee, T.-J., Chu, T.-M., Wolfinger, R. D., Cella, R., and Hanley-Bowdoin, L. 2008. Global analysis of Arabidopsis gene expression uncovers a complex array of changes impacting pathogen response and cell cycle during geminivirus infection. Plant Physiol. 148:436-454.

Bennetzen, J. L., Schmutz, J., Wang, H., Percifield, R., Hawkins, J., Pontaroli, A. C., Estep, M., Feng, L., Vaughn, J. N., Grimwood, J., Jenkins, J., Barry, K., Lindquist, E., Hellsten, U., Deshpande, S., Wang, X., Wu, X., Mitros, T., Triplett, J., Yang, X., Ye, C.-Y., Mauro-Herrera, M., Wang, L., Li, P., Sharma, M., Sharma, R., Ronald, P. C., Panaud, O., Kellogg, E. A., Brutnell, T. P., Doust, A. N., Tuskan, G. A., Rokhsar, D., and Devos, K. M. 2012. Reference genome sequence of the model plant Setaria. Nat. Biotech. 30:555-561.

Bragg, J. N., and Jackson, A. O. 2004. Barley stripe mosaic. Pages 456457 in: Viruses and Virus Diseases of Poaceae (Gramineae). H. Lapierre and P.-A. Signoret, eds. Institut National de la Recherche Agronomique, Paris.

Brkljacic, J., Grotewold, E., Scholl, R., Mockler, T., Garvin, D. F., Vain, P., Brutnell, T., Sibout, R., Bevan, M., Budak, H., Caicedo, A. L., Gao, C., Gu, Y., Hazen, S. P., Holt, B. F., Hong, S.-Y., Jordan, M., Manzaneda, A. J., Mitchell-Olds, T., Mochida, K., Mur, L. A. J., Park, C.-M., Sedbrook, J., Watt, M., Zheng, S. J., and Vogel, J. 2011. Brachypodium as a model for the grasses: Today and the future. Plant Physiol. 157:3-13.

Brodhun, F., and Feussner, I. 2011. Oxylipins in fungi. FEBS (Fed. Eur. Biochem. Soc.) J. 278:1047-1063.

Brutnell, T. P., Wang, L., Swartwood, K., Goldschmidt, A., Jackson, D. Zhu, X.-G., Kellogg, E., and Van Eck, J. 2010. Setaria viridis: A model for C4 photosynthesis. Plant Cell 22:2537-2544.

Buzen, F. G., Niblett, C. L., Hooper, G. R., Hubbard, J., and Newman, M. A. 1984. Further characterization of Panicum mosaic virus and its associated satellite virus. Phytopathology 74:313-318. 
Cabrera, O., and Scholthof, K.-B. G. 1999. The complex viral etiology of St. Augustine decline. Plant Dis. 83:902-904.

Cabrera, O., Roossinck, M., and Scholthof, K.-B. G. 2000. Genetic diversity of panicum mosaic virus satellite RNAs in St. Augustinegrass. Phytopathology 90:977-980.

Cao, S., Siriwardana, C., Kumimoto, R., and Holt, B. 2011. Construction of high quality Gateway entry libraries and their application to yeast two-hybrid for the monocot model plant Brachypodium distachyon. BMC Biotechnol. 11:53.

Chandra-Shekara, A. C., Navarre, D., Kachroo, A., Kang, H.-G., Klessig, D., and Kachroo, P. 2004. Signaling requirements and role of salicylic acid in HRT- and rrt-mediated resistance to Turnip crinkle virus in Arabidopsis. Plant J. 40:647-659.

Chern, M., Fitzgerald, H. A., Canlas, P. E., Navarre, D. A., and Ronald, P. C. 2005. Overexpression of a rice NPR1 homolog leads to constitutive activation of defense response and hypersensitivity to light. Mol. PlantMicrobe Interact. 18:511-520.

Chintakuntlawar, A. V., Zhou, X., Rajaiya, J., and Chodosh, J. 2010. Viral capsid is a pathogen-associated molecular pattern in adenovirus keratitis. PLOS Pathog. 6:e1000841. Published online.

Cui, Y., Lee, M. Y., Huo, N., Bragg, J., Yan, L., Yuan, C., Li, C., Holditch, S. J., Xie, J., Luo, M.-C., Li, D., Yu, J., Martin, J., Schackwitz, W., Gu, Y. Q., Vogel, J. P., Jackson, A. O., Liu, Z., and Garvin, D. F. 2012. Fine mapping of the Bsrl Barley stripe mosaic virus resistance gene in the model grass Brachypodium distachyon. PLOS One 7:e38333. Published online.

Dodds, P. N., and Rathjen, J. P. 2010. Plant immunity: Towards an integrated view of plant-pathogen interactions. Nat. Rev. Genet. 11:539548

Donald, R. G. K., and Jackson, A. O. 1994. Hordeiviruses. Pages 661-664 in: Encyclopedia of Virology. Vol. 2. R. G. Webster, A. Granoff, ed. Academic Press, San Diego, CA, U.S.A.

Dong, X. 2004. NPR1, all things considered. Curr. Opin. Plant Biol. 7:547-552.

Engelberth, J., Viswanathan, S., and Engelberth, M. 2011. Low concentrations of salicylic acid stimulate insect elicitor responses in Zea mays seedlings. J. Chem. Ecol. 37:263-266.

Feys, B. J., Moisan, L. J., Newman, M.-A., and Parker, J. E. 2001. Direct interaction between the Arabidopsis disease resistance signaling proteins, EDS1 and PAD4. EMBO (Eur. Mol. Biol. Organ.) J. 20:5400-5411.

French, R., and Stenger, D. C. 2003. Evolution of Wheat streak mosaic virus: Dynamics of population growth within plants may explain limited variation. Annu. Rev. Phytopathol. 41:199-214.

French, R., and Stenger, D. C. 2004 Wheat streak mosaic. Pages 602-604 in: Viruses and Virus Diseases of Poaceae (Gramineae). H. Lapierre and P.-A. Signoret, eds. Institut National de la Recherche Agronomique, Paris

Gadagkar, S. R., Rosenberg, M. S., and Kumar, S. 2005. Inferring species phylogenies from multiple genes: Concatenated sequence tree versus consensus gene tree. J. Exp. Zool. 304B:64-74.

Gerwick, W. H. 1994. Structure and biosynthesis of marine algal oxylipins. BBA-Lipid Lipid Met. 1211:243-255.

Goodstein, D. M., Shu, S., Howson, R., Neupane, R., Hayes, R. D., Fazo, J., Mitros, T., Dirks, W., Hellsten, U., Putnam, N., and Rokhsar, D. S. 2012. Phytozome: A comparative platform for green plant genomics. Nucleic Acids Res. 40:D1178-D1186.

Grass Phylogeny Working Group II. 2012. New grass phylogeny resolves deep evolutionary relationships and discovers $\mathrm{C}_{4}$ origins. New Phytol. 193:304-312

Hagborg, W. A. F. 1954. Dwarfing of wheat and barley by the barley stripe-mosaic (false stripe) virus. Can. J. Bot. 32:24-37.

Hanssen, I. M., Peter van Esse, H., Ballester, A.-R., Hogewoning, S. W. Parra, N. O., Paeleman, A., Lievens, B., Bovy, A. G., and Thomma, B. P. H. J. 2011. Differential tomato transcriptomic responses induced by Pepino mosaic virus isolates with differential aggressiveness. Plant Physiol. 156:301-318

Hong, S.-Y., Seo, P., Yang, M.-S., Xiang, F., and Park, C.-M. 2008. Exploring valid reference genes for gene expression studies in Brachypodium distachyon by real-time PCR. BMC Plant Biol. 8:112.

Huang, Z., Yeakley, J. M., Garcia, E. W., Holdridge, J. D., Fan, J.-B., and Whitham, S. A. 2005. Salicylic acid-dependent expression of host genes in compatible Arabidopsis-virus interactions. Plant Physiol. 137:11471159.

Hyde, J. L., Gardner, C. L., Kimura, T., White, J. P., Liu, G., Trobaugh, D. W., Huang, C., Tonelli, M., Paessler, S., Takeda, K., Klimstra, W. B., Amarasinghe, G. K., and Diamond, M. S. 2014. A viral RNA structural element alters host recognition of nonself RNA. Science 343:783-787.

International Brachypodium Initiative. 2010. Genome sequencing and analysis of the model grass Brachypodium distachyon. Nature 463:763768
Jackson, A. O., Lim, H.-S., Bragg, J., Ganesan, U., and Lee, M. Y. 2009. Hordeivirus replication, movement, and pathogenesis. Annu. Rev. Phytopathol. 47:385-422.

Jakubiec, A., Yang, S. W., and Chua, N.-H. 2012. Arabidopsis DRB4 protein in antiviral defense against Turnip yellow mosaic virus infection. Plant J. 69:14-25.

Jia, M.-A., Li, Y., Lei, L., Di, D., Miao, H., and Fan, Z. 2012. Alteration of gene expression profile in maize infected with a double-stranded RNA fijivirus associated with symptom development. Mol. Plant Pathol. 13:251-262.

Kachroo, P., Yoshioka, K., Shah, J., Dooner, H. K., and Klessig, D. F. 2000. Resistance to Turnip crinkle virus in Arabidopsis is regulated by two host genes and is salicylic acid dependent but NPR1, ethylene, and jasmonate independent. Plant Cell 12:677-690.

Kendall, A., McDonald, M., Bian, W., Bowles, T., Baumgarten, S. C., Shi, J., Stewart, P.L., Bullitt, E., Gore, D., Irving, T.C., Havens, W.M., Ghabrial, S.A., Wall, J. S., and Stubbs, G. 2008. Structure of flexible filamentous plant viruses. J. Virol. 82:9546-9554.

Larkin, M. A., Blackshields, G., Brown, N. P., Chenna, R., McGettigan, P. A., McWilliam, H., Valentin, F., Wallace, I. M., Wilm, A., Lopez, R., Thompson, J. D., Gibson, T .J., and Higgins, D. G. 2007. Clustal W and Clustal X version 2.0. Bioinformatics 23:2947-2948.

Lee, A., Cho, K., Jang, S., Rakwal, R., Iwahashi, H., Agrawal, G. K. Shim, J., and Han, O. 2004. Inverse correlation between jasmonic acid and salicylic acid during early wound response in rice. Biochem. Biophys. Res. Commun. 318:734-738

Lee, D.-S., Nioche, P., Hamberg, M., and Raman, C. S. 2008. Structural insights into the evolutionary paths of oxylipin biosynthetic enzymes. Nature 455:363-368.

Lee, M. Y., Yan, L., Gorter, F. A., Kim, B. Y. T., Cui, Y., Hu, Y., Yuan, C., Grindheim, J., Ganesan, U., Liu, Z., Han, C., Yu, J., Li, D., and Jackson, A. O. 2012. Brachypodium distachyon line Bd3-1 resistance is elicited by the Barley stripe mosaic virus triple gene block 1 movement protein J. Gen. Virol. 93:2729-2739.

Letunic, I., and Bork, P. 2007. Interactive Tree Of Life (iTOL): An online tool for phylogenetic tree display and annotation. Bioinformatics 23:127-128.

Livak, K. J., and Schmittgen, T. D. 2001. Analysis of relative gene expression data using real-time quantitative PCR and the $2^{-\Delta \Delta C T}$ method. Methods 25:402-408.

Love, A. J., Geri, C., Laird, J., Carr, C., Yun, B.-W., Loake, G. J., Tada, Y., Sadanandom, A., and Milner, J. J. 2012. Cauliflower mosaic virus protein P6 inhibits signaling responses to salicylic acid and regulates innate immunity. PLOS One 7:e47535. Published online.

Mandadi, K. K., and Scholthof, K.-B. G. 2012. Characterization of a viral synergism in the monocot Brachypodium distachyon reveals distinctly altered host molecular processes associated with disease. Plant Physiol. 160:1432-1452.

Mandadi, K. K., and Scholthof, K.-B. G. 2013. Plant immune responses against viruses: How does a virus cause disease? Plant Cell 25:14891505

Mur, L. A. J., Kenton, P., Atzorn, R., Miersch, O., and Wasternack, C. 2006. The outcomes of concentration-specific interactions between salicylate and jasmonate signaling include synergy, antagonism, and oxidative stress leading to cell death. Plant Physiol. 140:249-262.

Mur, L. A. J., Allainguillaume, J., Catalán, P., Hasterok, R., Jenkins, G., Lesniewska, K., Thomas, I., and Vogel, J. 2011. Exploiting the Brachypodium Tool Box in cereal and grass research. New Phytol. 191:334347.

Navia, D., Mendonça, R., Skoracka, A., Szydło, W., Knihinicki, D., Hein, G., da Silva Pereira, P., Truol, G., and Lau, D. 2013. Wheat curl mite, Aceria tosichella, and transmitted viruses: An expanding pest complex affecting cereal crops. Exp. Appl. Acarol. 59:95-143.

Pacheco, R., García-Marcos, A., Manzano, A., de Lacoba, M. G., Camañes, G., García-Agustín, P., Díaz-Ruíz, J. R., and Tenllado, F. 2012. Comparative analysis of transcriptomic and hormonal responses to compatible and incompatible plant-virus interactions that lead to cell death. Mol. Plant-Microbe Interact. 25:709-723.

Parker, L., Kendall, A., Berger, P. H., Shiel, P. J., and Stubbs, G. 2005. Wheat streak mosaic virus-Structural parameters for a Potyvirus. Virology 340:64-69.

Pearson, W. R. 1991. Searching protein sequence libraries: Comparison of the sensitivity and selectivity of the Smith-Waterman and FASTA algorithms. Genomics 11:635-650.

Petty, I. T. D., Hunter, B. G., Wei, N., and Jackson, A. O. 1989. Infectious Barley stripe mosaic virus RNA transcribed in vitro from full-length genomic cDNA clones. Virology. 171:342-349.

Pieterse, C. M. J., Van der Does, D., Zamioudis, C., Leon-Reyes, A., and Van Wees, S. C. M. 2012. Hormonal modulation of plant immunity. Annu. Rev. Cell Dev. Biol. 28:489-521. 
Postnikova, O., and Nemchinov, L. 2012. Comparative analysis of microarray data in Arabidopsis transcriptome during compatible interactions with plant viruses. Virol. J. 9:101.

Qiu, W., and Scholthof, K.-B. G. 2000. In vitro- and in vivo-generated defective RNAs of satellite panicum mosaic virus define cis-acting RNA elements required for replication and movement. J. Virol. 74:22472254.

Qiu, W., and Scholthof, K.-B. G. 2001. Defective interfering RNAs of a satellite virus. J. Virol. 75:5429-5432.

Redinbaugh, M., and Pratt, R. 2009. Virus resistance. Pages 251-270 in: Handbook of Maize: Its Biology. J. L. Bennetzen, S. C. Hake, ed. Springer, NY, U.S.A.

Saeed, A., Sharov, V., White, J., Li, J., Liang, W., Bhagabati, N., Braisted, J., Klapa, M., Currier, T., Thiagarajan, M., Sturn, A., Snuffin, M., Rezantsev, A., Popov, D., Ryltsov, A., Kostukovich, E., Borisovsky, I., Liu, Z., Vinsavich, A., Trush, V., and Quackenbush, J. 2003. TM4: A free, open-source system for microarray data management and analysis. Biotechniques 34:374-378.

Salzman, R. A., Brady, J. A., Finlayson, S. A., Buchanan, C. D., Summer, E. J., Sun, F., Klein, P. E., Klein, R. R., Pratt, L. H., Cordonnier-Pratt, M.-M., and Mullet, J. E. 2005. Transcriptional profiling of sorghum induced by methyl jasmonate, salicylic acid, and aminocyclopropane carboxylic acid reveals cooperative regulation and novel gene responses. Plant Physiol. 138:352-368

Satoh, K., Kondoh, H., Sasaya, T., Shimizu, T., Choi, I.-R., Omura, T., and Kikuchi, S. 2010. Selective modification of rice (Oryza sativa) gene expression by Rice stripe virus infection. J. Gen. Virol. 91:294305

Scholthof, K.-B. G. 1999. A synergism induced by satellite panicum mosaic virus. Mol. Plant-Microbe Interact. 12:163-166.

Schwessinger, B., and Ronald, P. C. 2012. Plant innate immunity: Perception of conserved microbial signatures. Annu. Rev. Plant Biol. 63:451482

Shimizu, T., Satoh, K., Kikuchi, S., and Omura, T. 2007. The repression of cell wall- and plastid-related genes and the induction of defense-related genes in rice plants infected with Rice dwarf virus. Mol. Plant-Microbe Interact. 20:247-254.

Shpaer, E. G., Robinson, M., Yee, D., Candlin, J. D., Mines, R., and Hunkapiller, T. 1996. Sensitivity and selectivity in protein similarity searches: A comparison of Smith-Waterman in hardware to BLAST and FASTA. Genomics 38:179-191.

Sill, W. H., and Pickett, R. C. 1957. A new virus disease of switchgrass, Panicum virgatum L. Plant Dis. Reptr. 41:241-249.

Smith, T. F., and Waterman, M. S. 1981. Identification of common molecular subsequences. J. Mol. Biol. 147:195-197.

Spoel, S. H., Koornneef, A., Claessens, S. M. C., Korzelius, J. P., Van Pelt, J. A., Mueller, M. J., Buchala, A. J., Métraux, J.-P., Brown, R., Kazan, K., Van Loon, L. C., Dong, X., and Pieterse, C. M. J. 2003. NPR1 modulates cross-talk between salicylate- and jasmonate-dependent defense pathways through a novel function in the cytosol. Plant Cell 15:760-770.
Stewart, C. L., Yuen, G. Y., Vogel, K., Pyle, J. D., and Scholthof, K.-B. G. 2013. Panicum mosaic virus-A potential threat to biofuel switchgrass production. Phytopathology 103:138.

Thaler, J. S., Humphrey, P. T., and Whiteman, N. K. 2012. Evolution of jasmonate and salicylate signal crosstalk. Trends Plant Sci. 17:260-270.

Trottet, M., and Gouis, J. L. 2004. Manipulation of resistance genes. Pages 180-186 in: Viruses and Virus Diseases of Poaceae (Gramineae). H. Lapierre and P.-A. Signoret, eds. Institut National de la Recherche Agronomique, Paris.

Turina, M., Maruoka, M., Monis, J., Jackson, A. O., and Scholthof, K.-B G. 1998. Nucleotide sequence and infectivity of a full-length cDNA clone of Panicum mosaic virus. Virology 241:141-155.

Turina, M., Desvoyes, B., and Scholthof, K.-B. G. 2000. A gene cluster encoded by Panicum mosaic virus is associated with virus movement. Virology 266:120-128.

Ventelon-Debout, M., Nguyen, T. T. H., Wissocq, A., Berger, C., Laudie, M., Piégu, B., Cooke, R., Ghesquière, A., Delseny, M., and Brugidou, C. 2003. Analysis of the transcriptional response to Rice yellow mottle virus infection in Oryza sativa indica and japonica cultivars. Mol. Genet. Genom. 270:253-262.

Verhage, A., van Wees, S. C. M., and Pieterse, C. M. J. 2010. Plant immunity: It's the hormones talking, but what do they say? Plant Physiol. 154:536-540.

Vogel, J., Gu, Y., Twigg, P., Lazo, G., Laudencia-Chingcuanco, D., Hayden, D., Donze, T., Vivian, L., Stamova, B., and Coleman-Derr, D. 2006. EST sequencing and phylogenetic analysis of the model grass Brachypodium distachyon. Theor. Appl. Genet. 113:186-195.

Weichert, H., Stenzel, I., Berndt, E., Wasternack, C., and Feussner, I. 1999. Metabolic profiling of oxylipins upon salicylate treatment in barley leaves - Preferential induction of the reductase pathway by salicylate. FEBS (Fed. Eur. Biochem. Soc.) Lett. 464:133-137.

Whitham, S. A., Yang, C., and Goodin, M. M. 2006. Global impact: Elucidating plant responses to viral infection. Mol. Plant-Microbe Interact. 19:1207-1215.

Yuan, Y., Zhong, S., Li, Q., Zhu, Z., Lou, Y., Wang, L., Wang, J., Wang, M., Li, Q., Yang, D., and He, Z. 2007. Functional analysis of rice NPR1-like genes reveals that OsNPR1/NH1 is the rice orthologue conferring disease resistance with enhanced herbivore susceptibility. Plant Biotechnol. J. 5:313-324.

Zhou, N., Tootle, T. L., Tsui, F., Klessig, D. F., and Glazebrook, J. 1998. PAD4 functions upstream from salicylic acid to control defense responses in Arabidopsis. Plant Cell 10:1021-1030.

Zhu, S., Jeong, R.-D., Venugopal, S. C., Lapchyk, L., Navarre, D., Kachroo, A., and Kachroo, P. 2011. SAG101 forms a ternary complex with EDS 1 and PAD4 and is required for resistance signaling against Turnip crinkle virus. PLOS Pathog. 7:e1002318. Published online.

\section{AUTHOR-RECOMMENDED INTERNET RESOURCE}

The Food and Agriculture Organization website: FAO.org 